\title{
Imaging characteristics of coronavirus disease 2019 (COVID-19) in pediatric cases: a systematic review and meta-analysis
}

\author{
Si-Tian Zang ${ }^{1,2}$, Xu Han ${ }^{3}$, Qi Cui ${ }^{1,2}$, Qing Chang ${ }^{1,2}$, Qi-Jun Wu ${ }^{1,2}$, Yu-Hong Zhao ${ }^{1,2}$ \\ ${ }^{1}$ Department of Clinical Epidemiology, Shengjing Hospital of China Medical University, Shenyang, China; ${ }^{2}$ Clinical Research Center, Shengjing \\ Hospital of China Medical University, Shenyang, China; ${ }^{3}$ Department of Pathology, the First Hospital of China Medical University, Shenyang, China \\ Contributions: (I) Conception and design: YH Zhao, QJ Wu; (II) Administrative support: YH Zhao, Q Chang; (III) Provision of study materials \\ or patients: YH Zhao, Q Chang, QJ Wu; (IV) Collection and assembly of data: ST Zang, X Han, Q Cui; (V) Data analysis and interpretation: All \\ authors; (VI) Manuscript writing: All authors; (VII) Final approval of manuscript: All authors. \\ Correspondence to: Yu-Hong Zhao, MD, PhD. Department of Clinical Epidemiology, Shengjing Hospital of China Medical University, No. 36 Sanhao \\ Street, Shenyang 110004, China. Email: zhaoyuhong@sj-hospital.org.
}

Background: The confirmed coronavirus disease 2019 (COVID-19) cases, caused by severe acute respiratory syndrome coronavirus 2 (SARS-CoV-2), have exceeded 21 million (with more than 775,000 fatalities), and the number of children with COVID-19 is also increasing. This study aimed to summarize the chest imaging characteristics of pediatric COVID-19 cases and provide a reference for the diagnosis and control of pediatric COVID-19.

Methods: The study protocol was registered in PROSPERO, number CRD42020177391. Studies related to pediatric COVID-19 imaging manifestations were accessed from PubMed, Web of Science, and the Cochrane library databases, without language limitations. The publication date was limited to April 1, 2020, and it was updated on May 1 and May 27, 2020. Data normalization was determined with the Freeman-Tukey double arcsine transformation. Summarized incidences with $95 \%$ confidence intervals of various imaging manifestations were assessed by random-effects models. Heterogeneity was assessed with meta-regression and subgroup analyses, robustness with sensitivity analyses; and publication biases with Egger's test.

Results: Twenty-three with 517 cases were included in this study. The summarized incidence of chest computed tomography abnormalities in pediatric COVID-19 cases was 70\%, which was lower than what has been seen in adults. The incidence of halo signs in pediatric COVID-19 cases was $26 \%$, which is rarely seen in adult COVID-19 cases. The incidences of ground-glass opacities (GGOs), GGOs and consolidations, consolidations, reverse halo signs, crazy paving signs, pleural effusion, bronchopneumonia-like signs, air bronchograms, and increased lung markings were 40\%, 25\%, 10\%, 2\%, 4\%, 1\%, 15\%, 12\%, and 31\%, respectively. Pericardial effusions were found in the computed tomography images of adult COVID-19 cases but were scarcely seen in the computed tomography images of pediatric COVID-19 cases. The incidences of bilateral lesions, unilateral lesions, and peripheral lesions were $35 \%, 22 \%$, and $26 \%$, respectively.

Conclusions: Chest computed tomography imaging of pediatric COVID-19 cases resulted in various abnormalities that were milder than those of adults. This study will hopefully provide a reference to help identify pediatric COVID-19 cases.

Keywords: Coronavirus disease 2019 (COVID-19); imaging characteristics; meta-analysis; pediatrics; severe acute respiratory syndrome coronavirus $2(\mathrm{SARS}-\mathrm{CoV}-2)$

Submitted Sep 05, 2020. Accepted for publication Dec 04, 2020.

doi: $10.21037 / \mathrm{tp}-20-281$

View this article at: http://dx.doi.org/10.21037/tp-20-281

^ ORCID: 0000-0001-5047-0500. 


\section{Introduction}

At the end of 2019, several unexplained pneumonia cases in Wuhan, a city with 11 million permanent residents in central China, drew public attention (1). The pneumonia was determined to be caused by a new single-stranded positive-sense RNA coronavirus, named severe acute respiratory syndrome coronavirus (SARS-CoV-2), and had $79 \%$ similarity to the SARS-CoV RNA sequence (2). Then, the World Health Organization (WHO) designated coronavirus disease 2019 (COVID-19) a pandemic on March 11, 2020 (3). Being highly contagious, COVID-19 has severely endangered global public health (4). Up until August 20,2020, the number of confirmed cases has exceeded 21 million (including more than 775,000 fatalities) worldwide, which has affected more than 200 countries and regions (5). Thus, the early detection and isolation of confirmed cases are crucial to the control of SARS-CoV-2 transmission.

Chest radiography and computed tomography (CT) are auxiliary methods to help firm COVID-19 diagnoses with reverse transcription-polymerase chain reaction (RT-PCR). As the basis for the clinical COVID-19 staging, CT imaging is more precise than RT-PCR to detect COVID-19 infection (1). A single meta-analysis summarized adult COVID-19 CT characteristics and showed that the incidence of ground-glass opacities (GGOs) was $83 \%$ (6). However, fewer pediatric cases have been reported worldwide in the early stages of the pandemic. As the pandemic spread, the number of children with COVID-19 has also increased dramatically (4). Until September 10, 2020, the number of confirmed pediatric cases has exceeded 500,000 in the United States, accounting for about $10 \%$ of the total confirmed cases (7).

Several articles have been published involving the CT imaging characteristics of pediatric COVID-19 cases (8-10). However, there is still a lack of corresponding meta-analyses. In this study, findings were published that summarized a comprehensive review and metaanalysis with a complete evaluation of CT characteristics in pediatric COVID-19 cases. This meta-analysis could be used as a reference for pediatricians to identify pediatric SARS-CoV-2 infection. It could also be helpful for experts in the control of the pediatric COVID-19 pandemic.

We present the following article in accordance with the PRISMA reporting checklist (available at http://dx.doi. org/10.21037/tp-20-281).

\section{Methods}

The study protocol was registered in the international prospective register of systematic reviews (https://www.crd. york.ac.uk/PROSPERO), number CRD42020177391.

\section{Study retrieval}

Articles were retrieved from PubMed, Web of Science, and the Cochrane library databases, with time limitation to April 1, 2020. The search queries are shown in Table S1. According to established practices, our searches were updated twice using the same search queries on May 1 and May 27, 2020. Chest imaging, COVID-19, and pediatric cases were terms applied to construct search queries, and synonyms were based on the Medical Subject Headings $(\mathrm{MeSH})$ and PubMed database entry terms. Moreover, other COVID-19 synonyms are available at https://www. crd.york.ac.uk/PROSPERO/\#searchadvanced, specified by the National Institute for Health Research. Furthermore, related references were evaluated to potentially obtain additional eligible studies.

\section{Study selection}

The studies included in this meta-analysis had to meet all the criteria listed below. First, the COVID-19 cases needed original, available, and accurate imaging characteristics, such as lesion densities, distributions, and morphologies. The included cases also needed to be less than 18 years old and included newborns, infants, preschool children, and school-age children. The study was defined as a crosssectional, case-series, case report, case-control, or cohort study, and each study included at least five cases.

Studies with at least one of the following characteristics were excluded: duplicated studies, studies with secondary imaging characteristics, unavailable or ambiguous studies, studies with patients infected with other viruses, such as SARS-CoV, and studies with patients who were greater than 18 years of age. Studies defined as letters, reviews, metaanalyses, editorials, or comments and those with studies with fewer than five cases were also excluded.

After excluding duplicated citations, the titles, abstracts, and full texts of the retrieved studies were evaluated in sequence according to the criteria listed described that included all qualified studies. Screening studies were performed by two authors independently, and disagreements between the two were mediated by the third author. Moreover, for cases with several CT examinations 
after admission, the first one was included in the study.

\section{Data extraction}

The number of cases on various imaging abnormalities (such as lesion density, distribution, and morphology, among others) was extracted. Meanwhile, the following research characteristics were extracted, including the first author, location (city, province/autonomous region, and country), study design type, study duration, diagnosis basis of COVID-19, sample size (male/female), mean or median case age, and epidemiologic history including exposure to confirmed, suspected COVID-19 cases or Wuhan. Additional characteristics included the number of asymptomatic cases. Literature data extractions were completed independently by two authors, and disagreements between the two were mediated by the third author.

\section{Quality assessment}

Tools provided by the National Heart, Lung, and Blood Institute were used to assess the quality of the included articles (11). Based on the characteristics of the included articles, the quality assessment tools used to evaluate case series studies and cohort studies were tailed into tables with eight and nine questions, respectively. Article quality was assessed independently by two authors, and disagreements were mediated by the third author.

\section{Statistical analysis}

Random-effects models were applied to pool the summarized incidences with $95 \%$ confidence intervals (CIs) of imaging characteristics. The research weights were calculated by the inverse variance method. The $\mathrm{Q}$ test was conducted to detect the significance of heterogeneity among the included research results. Moreover, the I squared $\left(\mathrm{I}^{2}\right)$ value was used to quantify heterogeneity, and the four intervals of $(0,25 \%),(25 \%, 50 \%),(50 \%, 75 \%)$, and $(75 \%, 100 \%)$ represented no, low, medium and high heterogeneity, respectively.

For the researched items with greater than or equal to eight included studies, the source of heterogeneity among the studies was explored using meta-regression and subgroup analyses. The research location (Wuhan $v$ s. outside Wuhan), male-to-female ratio $(\leq 1 v s .>1)$, and the number of cases $(5-20 v s$. $>20)$ were considered in the metaregression and subgroup analyses. In addition, the incidence of the remaining articles was summarily extracted by removing one included article at a time to detect the impact of removing one article on the overall incidence of included articles, namely a sensitivity analysis. Furthermore, the publication biases of the included articles were evaluated using Egger's test. We used Stata software (version 15.0, StataCorp LLC, USA) for data analyses, and $\mathrm{P}$ values $<0.05$ indicated a statistical difference.

\section{Results}

\section{Retrieval and selection results}

A total of 364 citations were retrieved, of which 99, 260, five, and five were from PubMed, Web of Science, the Cochrane library, and the secondary search of references of pertinent articles, respectively. After excluding 72 duplicate articles, 254 and five articles were excluded based on title and abstract assessments, respectively. Of the 42 articles eligible for full-text evaluation, 15 articles were excluded. These included five with insufficient data, four with fewer than five cases, four reviews, one with ambiguous data, and one with only asymptomatic cases. Thus, 23 articles (810,12-31) with 517 pediatric COVID-19 cases were eligible for the systematic review and meta-analysis (Figure 1).

\section{Study characteristics}

The characteristics of the included studies are listed in Table 1 and Table S2. With 282 (55.55\%) males and 235 ( $45.45 \%$ ) females (the ratio of males to females of $0.43-4$ ), the 23 eligible studies were from 26 cities in 17 provinces, autonomous regions, or municipalities of China. Seven $(30.43 \%)$ were from Hubei province, including five (21.74\%) from Wuhan $(15,16,22,27,28)$, one $(4.35 \%)$ from Yichang (12), and one (4.35\%) from Xiangyang (19). Among the 23 included studies, one (4.35\%) was a case report (8), $21(91.30 \%)$ were case series studies $(9,10,12-16,18-31)$, and one $(4.35 \%)$ was a cohort study (17). Except for the admission times not reported in three articles $(8,16,29)$, the 373 pediatric COVID-19 cases in the remaining 20 articles were enrolled from January 1 to March 17, 2020. Except for the age of cases not reported in one article (16), the mean or median ages in the remaining 22 articles were $1-14.5$ years old. In terms of epidemiologic histories, a total of 215 cases had been exposed to confirmed or suspected COVID-19 cases with a proportion of $0-100 \% ; 53$ cases had been exposed in Wuhan with a proportion of $0-44 \%$; 


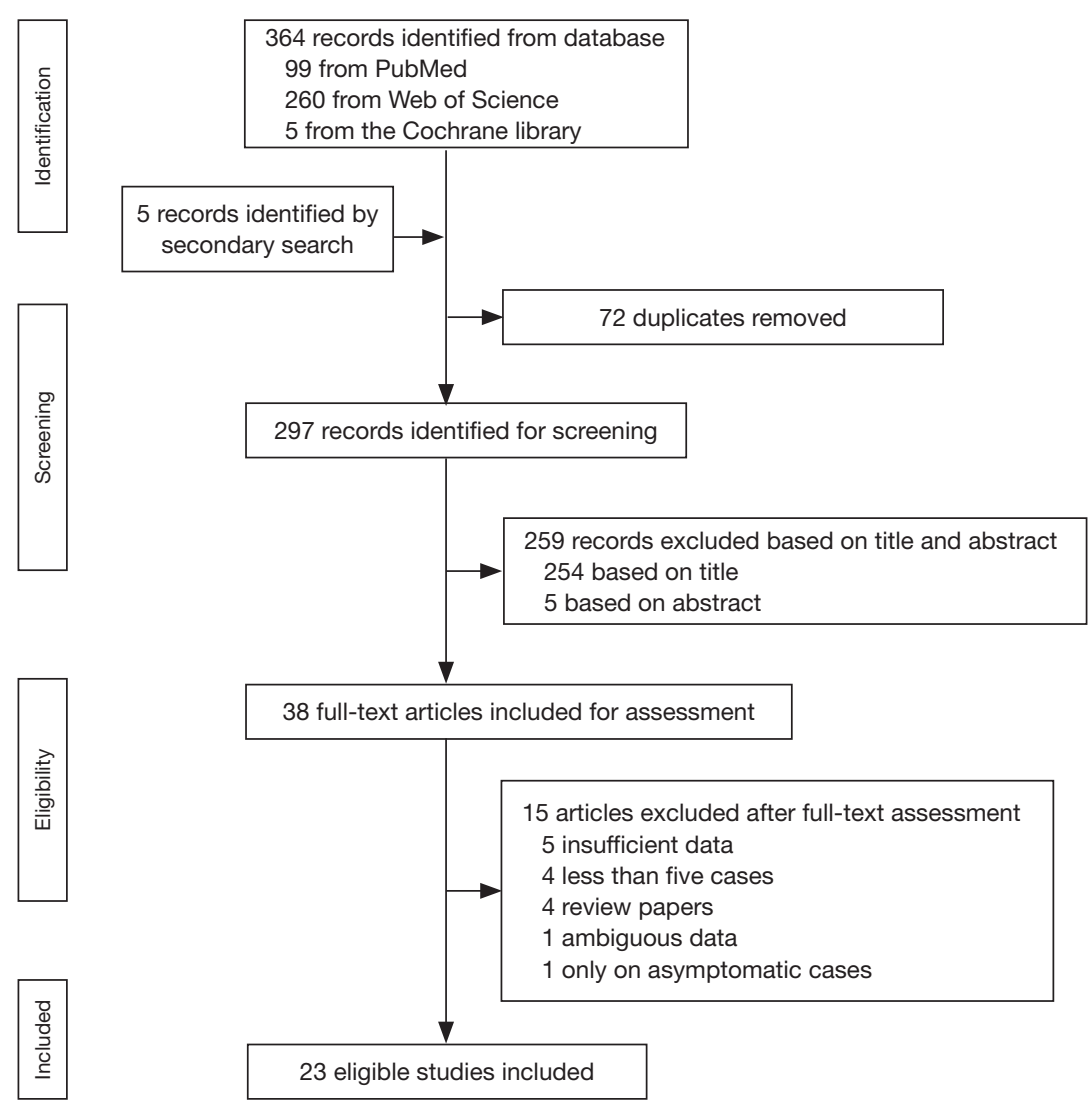

Figure 1 A flow chart of the study inclusion.

127 cases have been exposed to both, with a proportion of $0-91.30 \%$; and 39 cases had an unclear epidemiological history, with a proportion of proportion $0-35 \%$. The number of asymptomatic cases was 145 , with a proportion of proportion $0-100 \%$, and the remaining cases had fever, cough, sputum, and diarrhea, among other symptoms.

\section{Quality assessment}

The details of the case series and cohort study quality assessments are listed in Tables S3,S4, respectively. Eight (34.78\%) studies were of good quality, and fifteen (65.22\%) studies were of fair quality.

\section{Chest radiographic characteristics}

Chest radiographs were performed in only one article (14) on nine pediatric COVID-19 cases. The results showed that four cases had bronchial vascular shadow abnormalities and two had increased hilar shadows.

\section{CT imaging characteristics}

CT examinations were performed in 23 studies with 514 pediatric COVID-19 cases. Three hundred and sixty-seven cases had various abnormalities that were summarized as CT abnormalities. The summarized incidences of CT abnormality and publication biases are detailed in Table 2 . The overall incidence of CT abnormality was 70\% $(95 \%$ CI: $60-79 \%)$, with a medium heterogeneity $\left(\mathrm{I}^{2}=74.94 \%\right.$; Figure 2). Publication bias was also found.

\section{Manifestations of CT abnormality}

In pediatric COVID-19 cases, GGOs were the most common abnormalities on CT imaging with an incidence of $40 \%$ (95\% CI: $29-51 \%$ ) (Figure $3 A$ ). GGOs and consolidations, halo signs, and increased lung markings were also common with incidences of $25 \%$ (95\% CI: $8-46 \%$ ), $26 \%$ (95\% CI: $7-51 \%$ ), and $31 \%$ (95\% CI: $23-40 \%$ ), respectively (Figure $3 B, C, D)$. Moreover, the incidences of air bronchograms, bronchopneumonia-like 
Table 1 Imaging characteristics of pediatric COVID-19 cases included in the review and meta-analysis ${ }^{\dagger}$

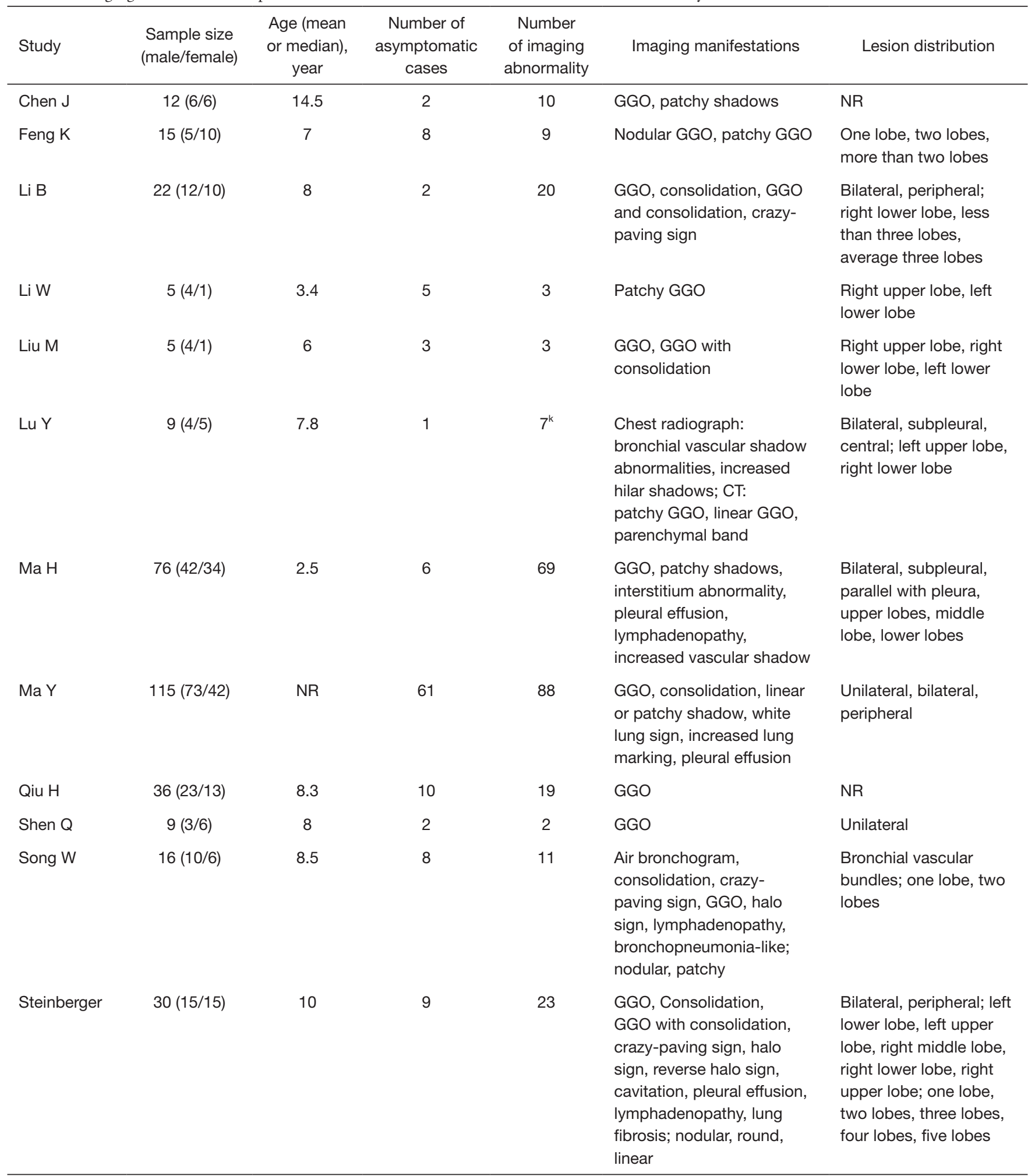

Table 1 (continued) 
Table 1 (continued)

\begin{tabular}{|c|c|c|c|c|c|c|}
\hline Study & $\begin{array}{l}\text { Sample size } \\
\text { (male/female) }\end{array}$ & $\begin{array}{l}\text { Age (mean } \\
\text { or median), } \\
\text { year }\end{array}$ & $\begin{array}{l}\text { Number of } \\
\text { asymptomatic } \\
\text { cases }\end{array}$ & $\begin{array}{l}\text { Number } \\
\text { of imaging } \\
\text { abnormality }\end{array}$ & Imaging manifestations & Lesion distribution \\
\hline $\operatorname{Tan} \mathrm{X}$ & $13(4 / 9)$ & 8 & 2 & 6 & $\begin{array}{l}\text { GGO, stringy shadow, } \\
\text { patchy shadow }\end{array}$ & $\begin{array}{l}\text { Left lower lobe, left } \\
\text { upper lobe, right lower } \\
\text { lobe }\end{array}$ \\
\hline $\operatorname{Tan} Y$ & $10(3 / 7)$ & 7 & 2 & 5 & $\begin{array}{l}\text { GGO, bronchopneumonia, } \\
\text { thickened bronchial wall, } \\
\text { increased lung marking, } \\
\text { nodular shadow }\end{array}$ & $\begin{array}{l}\text { Bilateral, unilateral; } \\
\text { lower lobes, left lower } \\
\text { lobe. }\end{array}$ \\
\hline Wu H & $\begin{array}{c}23(9 / 14 ; 22 \\
\text { with CT scan) }\end{array}$ & 5.6 & 3 & 12 & $\begin{array}{l}\text { Patchy GGO, patchy } \\
\text { consolidation }\end{array}$ & $\begin{array}{l}\text { Bilateral lower lobes, } \\
\text { bilateral upper and } \\
\text { lower lobes, unilateral, } \\
\text { subpleural; left lower } \\
\text { lobe, left upper lobe, } \\
\text { right upper lobe }\end{array}$ \\
\hline Xia W & $20(13 / 7)$ & 2.1 & 2 & 20 & $\begin{array}{l}\text { Halo sign, grid shadow; } \\
\text { nodular }\end{array}$ & $\begin{array}{l}\text { Bilateral, unilateral, } \\
\text { subpleural. }\end{array}$ \\
\hline Zhu L & $10(5 / 5)$ & 9.2 & 3 & 5 & GGO & Bilateral, unilateral \\
\hline
\end{tabular}

${ }^{\dagger}$, in only one article, chest radiographs and CT tests were performed on pediatric COVID-19 cases, and in the remaining 22 articles, only CT tests were performed on COVID-19 cases. COVID-19, coronavirus disease 2019; CT, computed tomography; GGO, ground-glass opacity; NR, not report; SARS-CoV-2, severe acute respiratory syndrome coronavirus 2. 
Table 2 Pooled incidences of computed tomography manifestations in pediatric COVID-19 cases

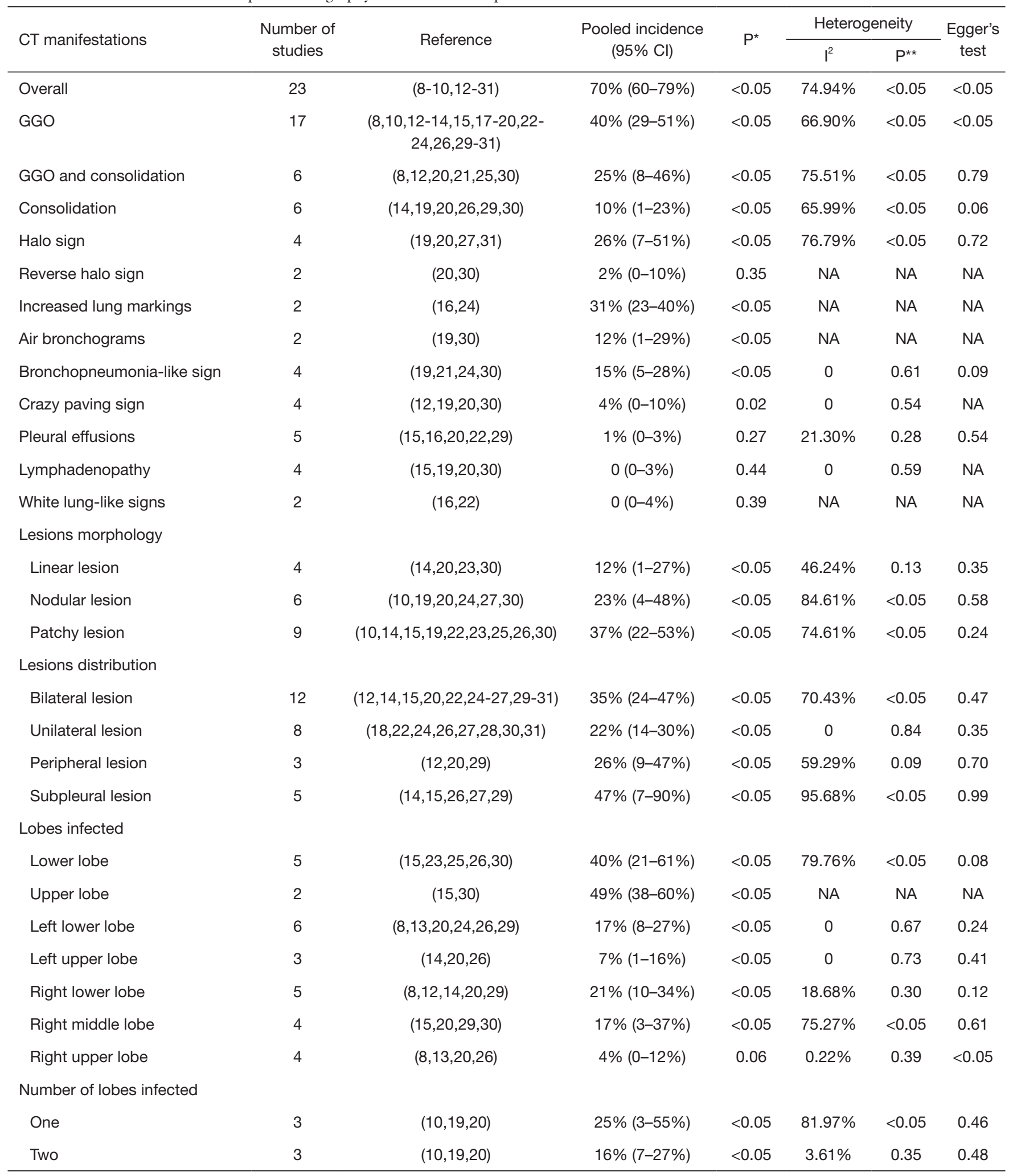

*Significance of summarized incidences. ${ }^{\star}$ Significance of heterogeneity. $\mathrm{P}<0.05$ was regarded as indication of statistical significance. COVID-19, coronavirus disease 2019; Cl, confidence interval; CT, computed tomography; GGO, ground-glass opacity; NA, not available. 


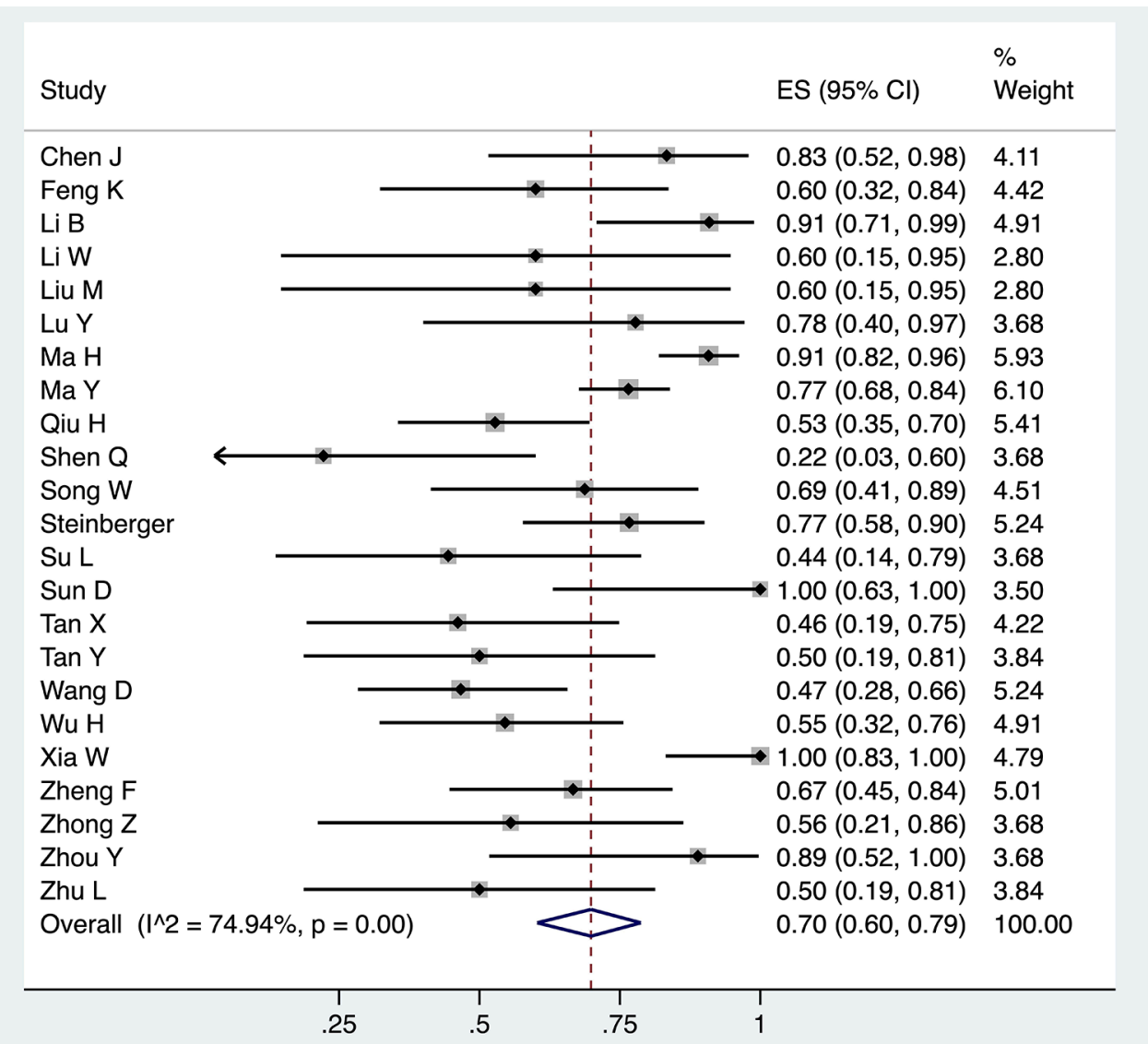

Figure 2 A forest plot shows the incidence of abnormal computed tomography (CT) findings in pediatric coronavirus disease 2019 (COVID-19) cases. The solid diamond and corresponding line represent the effect size (ES) and 95\% confidence interval (CI) of each article. The bottom diamond represents the summarized incidence of abnormal CT finding is 70\% (95\% CI: 60-79\%), with medium heterogeneity $\left(\mathrm{P}=0.00, \mathrm{I}^{2}=74.94 \%\right)$.

signs, consolidation, crazy paving signs, lymphadenopathy, pleural effusions, reverse halo sign, and white lung-like signs were $12 \%$ (95\% CI: 1-29\%), 15\% (95\% CI: 5-28\%), 10\% (95\% CI: $1-23 \%$ ), 4\% (95\% CI: 0-10\%), 0 (95\% CI: $0-3 \%), 1 \%$ (95\% CI: $0-3 \%), 2 \%$ (95\% CI: $0-10 \%)$, and $0 \%(95 \%$ CI: $0-4 \%)$, respectively (Figure S1). Furthermore, bronchitis, bronchial wall thickening, and pleural thickening were found in two of nine cases, one of ten cases, and one of nine cases in the literature, respectively $(21,24,30)$.

Publication bias was found regarding GGOs. However, no publication bias was found regarding GGOs with consolidation, consolidations alone, halo signs, bronchopneumonia-like signs, and pleural effusions. Publication biases on crazy paving signs and lymphadenopathy were unavailable because only two included studies had nonzero positive cases. In addition, publication biases and the heterogeneity of air bronchial shadows, increased lung markings, reverse halo signs, and white lung-like signs were unavailable because only two studies were available.

\section{Lesion morphologies}

The CT imaging of pediatric COVID-19 cases showed three lesion types: linear, nodular, and patchy with incidences of $12 \%$ (95\% CI: 1-27\%), $23 \%$ (95\% CI: $4-48 \%$ ), and $37 \%$ (95\% CI: $22-53 \%$ ), respectively (Figure S2). No publication bias was found. It should be mentioned that round lesions were also found in three of thirty cases in this study (14).

\section{Lesion distributions}

In pediatric COVID-19 cases, the incidences of bilateral lesions, unilateral lesions, peripheral lesions, and subpleural 
A

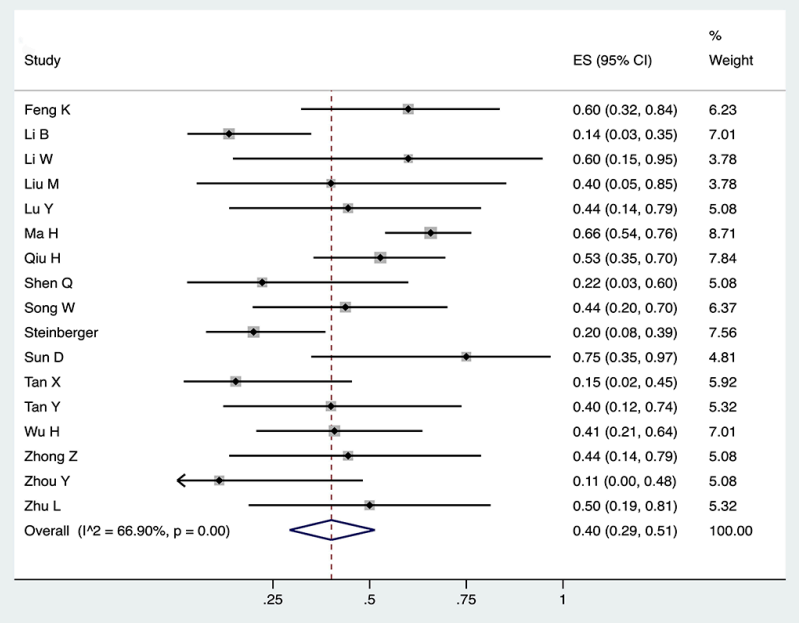

C

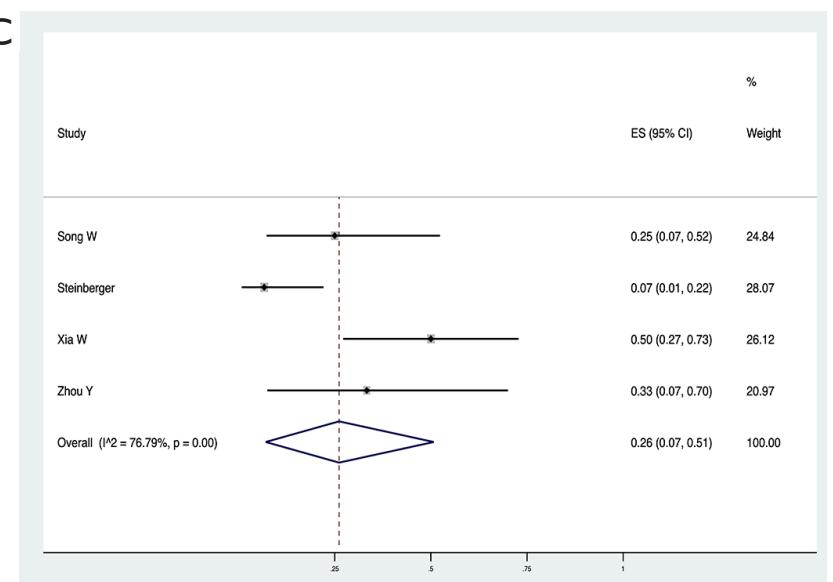

B

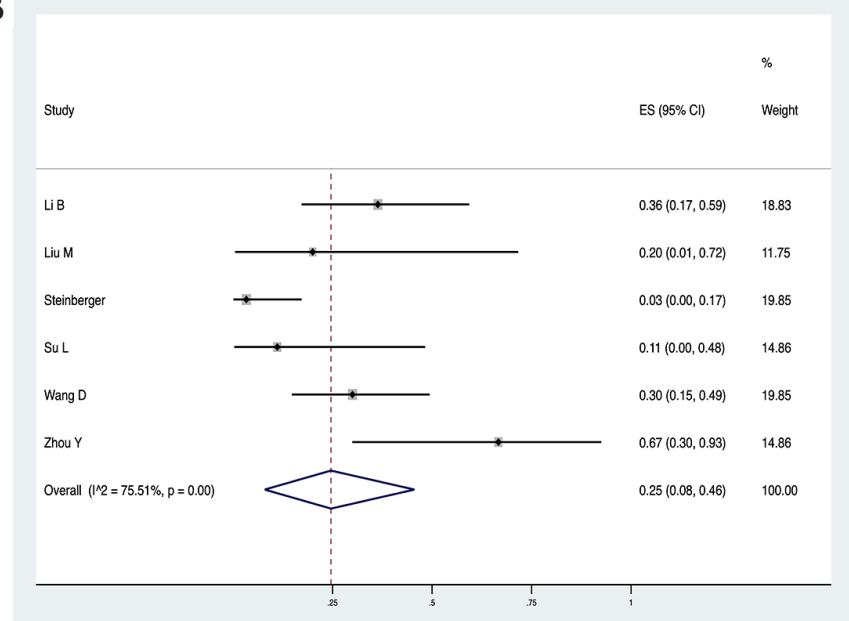

D

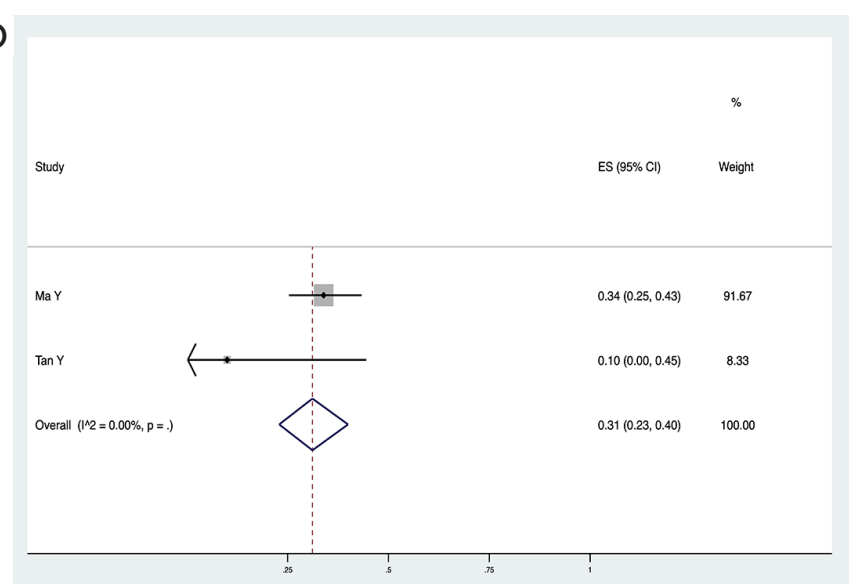

Figure 3 Forest plots show the incidences of abnormal computed tomography (CT) findings in pediatric coronavirus disease 2019 (COVID-19) cases. The solid diamond and corresponding line represent the effect size (ES) and 95\% confidence interval (CI) of each article. The bottom diamond represents the summarized incidence of abnormal CT findings. The incidences of (A) ground-glass opacities (GGOs), (B) GGOs and consolidation, (C) halo signs, (D) increased lung markings were 40\% (95\% CI: 29-51\%), 25\% (95\% CI: 8-46\%), 26\% (95\% CI: 7-51\%), and 31\% (95\% CI: 23-40\%), respectively.

lesions were 35\% (95\% CI: 24-47\%), 22\% (95\% CI: $14-$ 30\%), 26\% (95\% CI: 9-47\%), and 47\% (95\% CI: 7-90\%), respectively (Figure S3). No publication bias was found. Furthermore, lesions were also found in central, bronchial vascular, and interlobular locations, respectively $(14,19,30)$.

\section{Lung lobes infected}

The incidence of infection in the upper and lower lung lobes were 49\% (95\% CI: 38-60\%) and 40\% (95\% CI: $21-61 \%)$, respectively. The incidence of infection in the left lower lobe, left upper lobe, right lower lobe, right middle lobe, and right upper lobe were 17\% (95\% CI: 8-27\%), 7\% (95\% CI: 1-16\%), 21\% (95\% CI: 10-34\%), $17 \%$
(95\% CI: $3-37 \%$ ), and 4\% (95\% CI: 0-12\%), respectively (Figure S4). The incidence of infection in one lobe and two lobes were 25\% (95\% CI: 3-55\%) and 16\% (95\% CI: $7-27 \%$ ), respectively (Figure S5). Intriguingly, in one article of 30 cases, one case had a three-lobe infection, and another had a four-lobe infection (20).

Publication bias was found regarding right upper lobe infections. No publication bias was found on the infection regarding lower lobe, left lower lobe, left upper lobe, right lower lobe, right middle lobe, one lobe, and twolobe infections. Publication biases and heterogeneity of the upper lobe infection were unavailable because only two studies were summarized. 


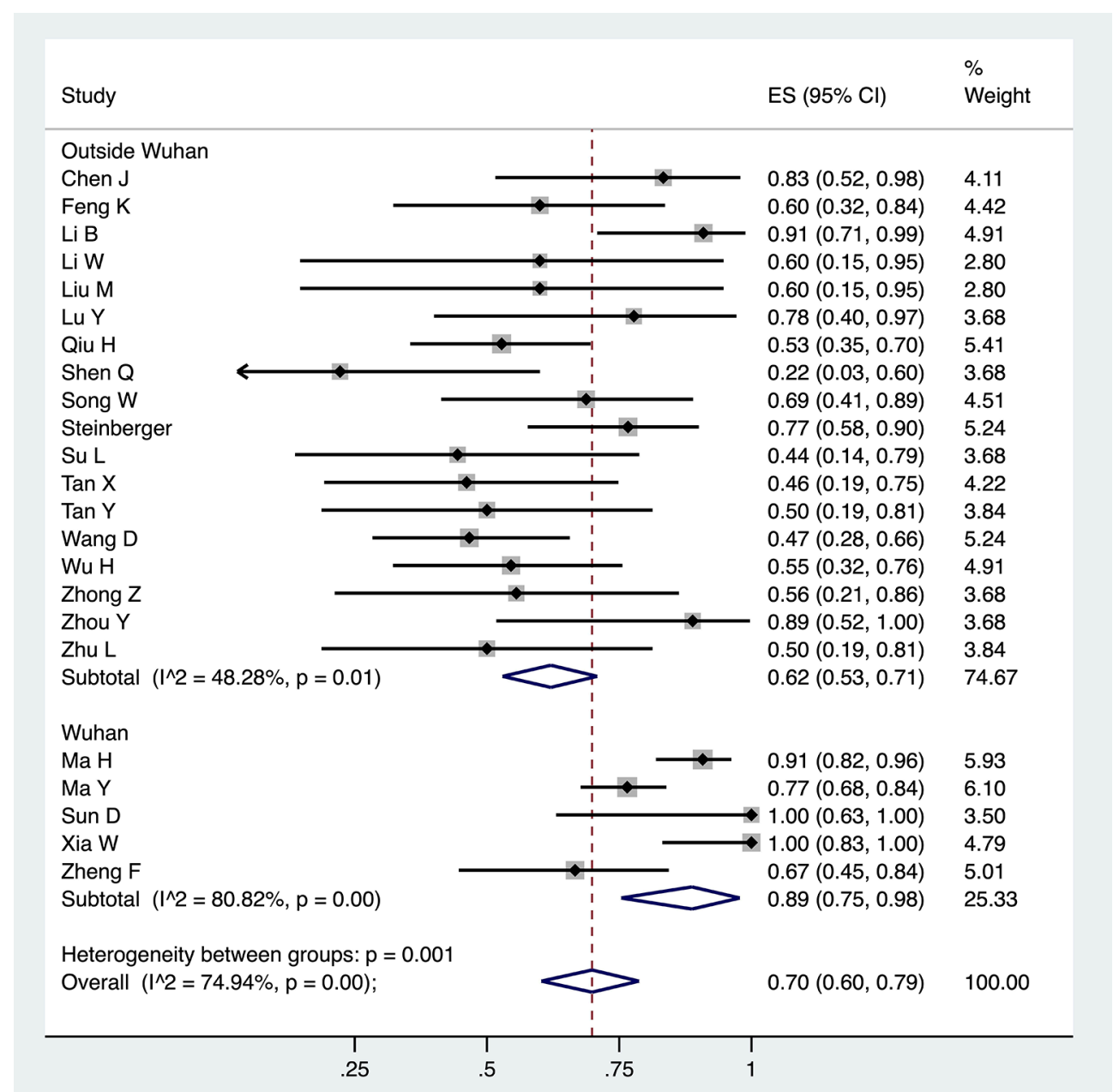

Figure 4 Forest plots show the subgroup analyses of abnormal computed tomography (CT) findings in pediatric coronavirus disease 2019 (COVID-19) cases based on the research location (Wuhan vs. outside Wuhan). The solid diamond and corresponding line represent the effect size (ES) and 95\% confidence interval (CI) of each article. The bottom diamond represents the summarized incidence of abnormal CT findings. The incidences of abnormal CT findings in pediatric COVID-19 cases in Wuhan and outside Wuhan are 89\% (95\% CI: 75-98\%) and $62 \%$ (95\% CI: $53-71 \%)$, respectively.

\section{Meta-regression, subgroup analyses, and sensitivity analyses}

Meta-regression analyses revealed that study sites were related to the heterogeneity among the different CT abnormalities and the heterogeneities between different GGO incidences. The male-to-female ratios and the number of cases were not the cause of the heterogeneity. Additionally, subgroup analyses showed that, for the CT abnormalities among the Wuhan studies, male-tofemale ratios $>1$, and studies with $>20$ cases had high heterogeneities (Figures 4-6, Table S5). For the GGOs, the heterogeneity of studies with $>20$ cases was high.
Meta-regression analyses showed that the study site, male-to-female ratio, and the number of cases were not related to heterogeneity in studies with patchy and bilateral lesions. Additionally, subgroup analyses showed that heterogeneity was high for patchy lesions among studies with 5-20 cases. Heterogeneity was high for bilateral lesions among studies with male-to-female ratios greater than one. No heterogeneity was found among studies with unilateral lesions (Tables S6-S9). Sensitivity analyses showed that the summarized incidences were not affected by individual studies included in the metaanalysis (Figure S6). 


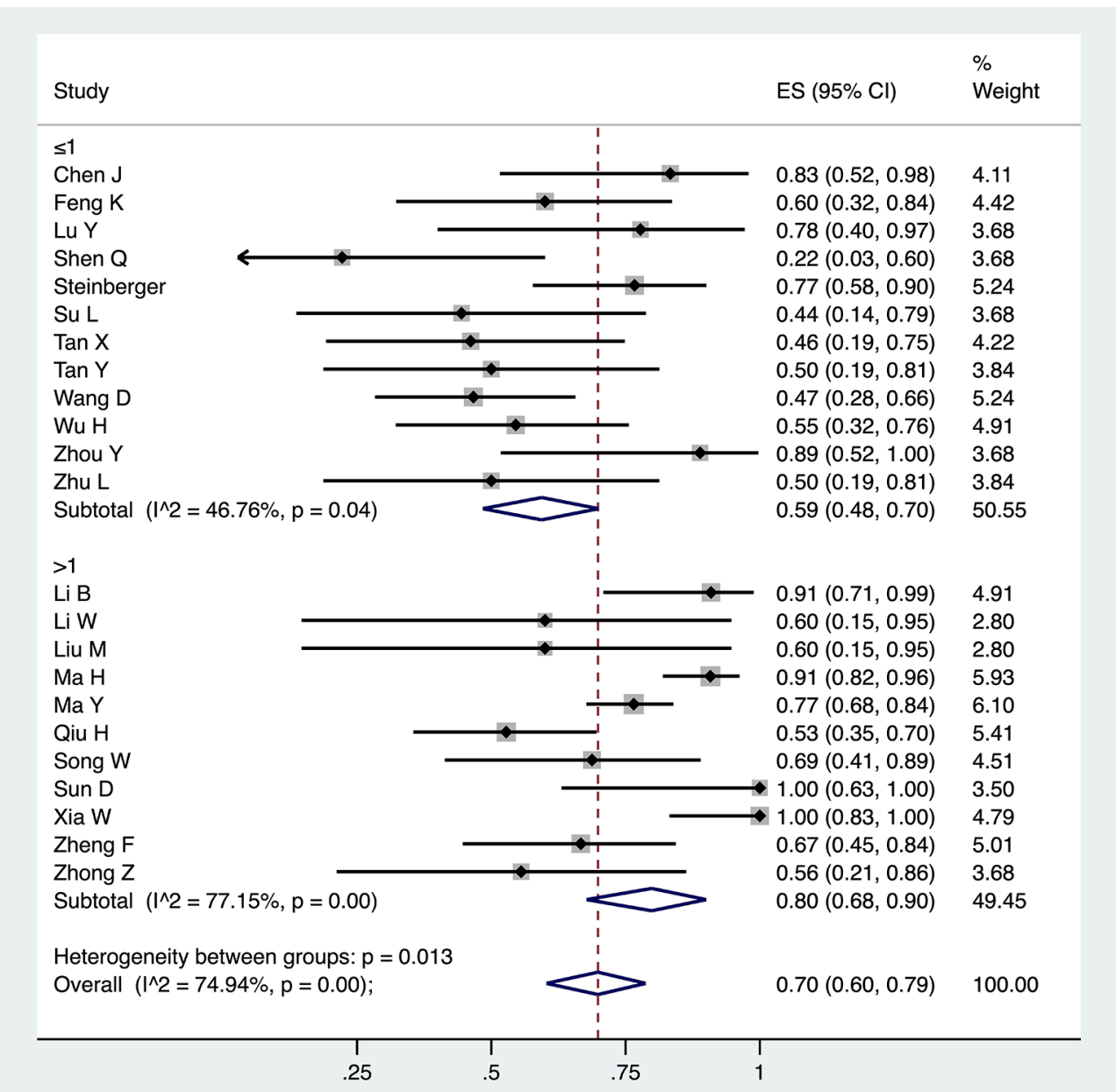

Figure 5 Forest plots show the subgroup analyses of abnormal computed tomography (CT) findings in pediatric coronavirus disease 2019 (COVID-19) cases based on the male-to-female ratio ( $\leq 1 v s .>1)$. The solid diamond and corresponding line represent the effect size (ES) and $95 \%$ confidence interval (CI) of each article. The bottom diamond represents the summarized incidence of abnormal CT findings. The incidences of abnormal CT findings in studies with male-to-female ratios $\leq 1$ and >1 are 59\% (95\% CI: 48-70\%) and $80 \%$ (95\% CI: 68-90\%), respectively.

\section{Discussion}

Our review and meta-analysis indicated that the proportion of pediatric COVID-19 cases examined with chest CT imaging was high. A total of 517 cases from 23 studies were included in this study. The summarized incidence of CT abnormalities in pediatric COVID-19 cases was 70\%, which was lower than what has been seen in adults (6). CT findings in children are similar to those in adults, but the symptoms are lighter (32). Similarly, clinical symptoms, such as dyspnea, diarrhea, and rhinorrhea, caused by COVID-19 infection have lower incidences in pediatric cases than that in adult cases (33). At the beginning of the epidemic, there were very few children with severe diseases. With the development of the epidemic situation and more and more severe children, the proportion of children with different degrees of disease in the included studies was different, which led to heterogeneity.

Nearly $90 \%$ of confirmed cases are adults over 30 years old (34). People with chronic diseases, such as (cardiovascular disease and diabetes), and smokers are more likely to be infected. Therefore, one of the reasons why children are less likely to be infected with SARS-CoV-2 than adults is that chronic diseases and smokers are rare among children (35). The mortality rate of COVID-19 among minors is $1 / 20$ of that of adults (36). The mortality 


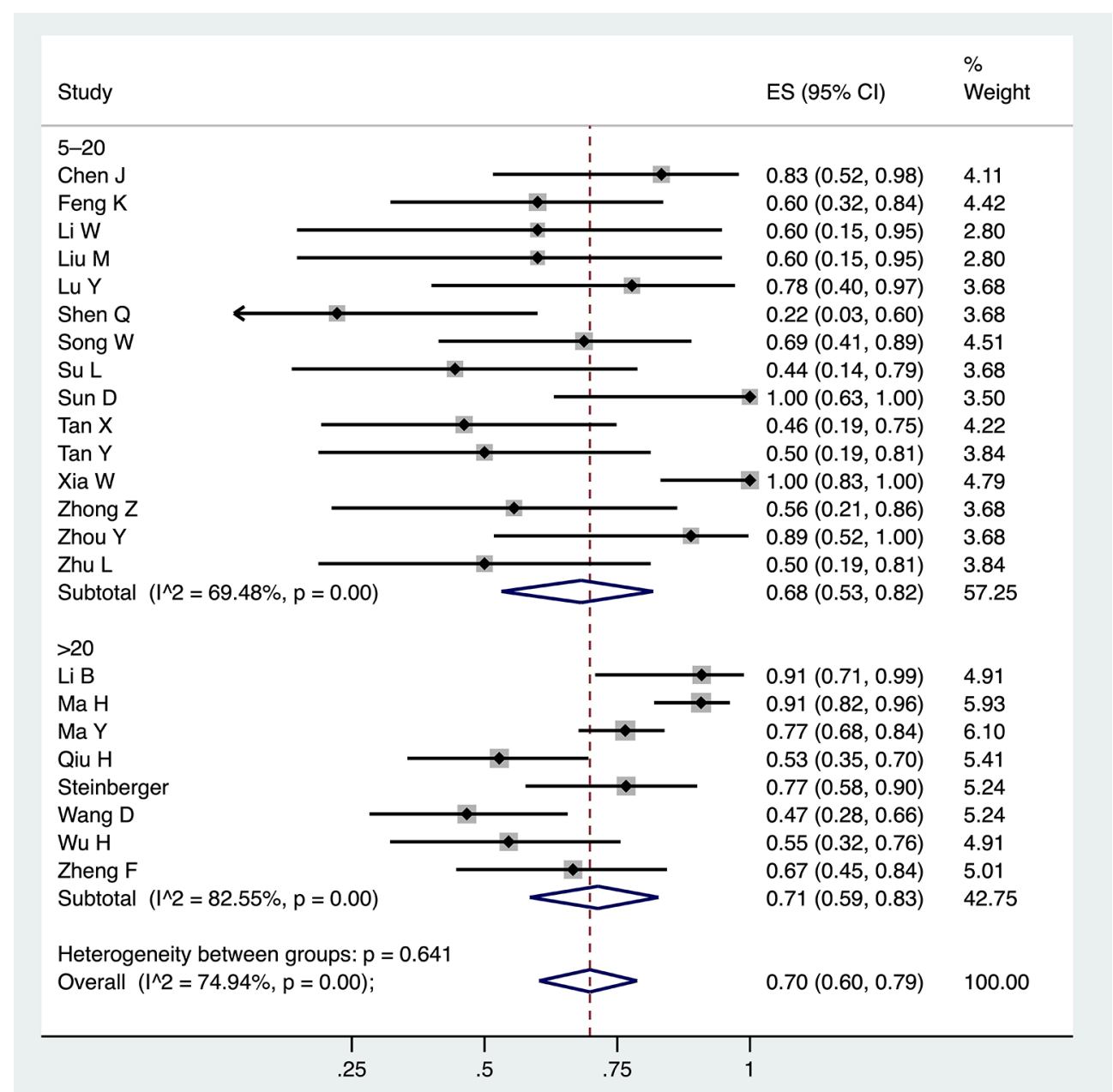

Figure 6 Forest plots show the subgroup analyses of abnormal computed tomography (CT) findings in pediatric coronavirus disease 2019 (COVID-19) cases based on the number of cases (5-20 vs. >20). The solid diamond and corresponding line represent the effect size (ES) and $95 \%$ confidence interval (CI) of each article. The bottom diamond represents the summarized incidence of abnormal CT findings. The incidences of abnormal CT findings in studies with 5-20 pediatric COVID-19 cases and >20 pediatric COVID-19 cases are 68\% (95\% CI: $53-82 \%$ ) and $71 \%$ (95\% CI: 59-83\%), respectively.

rate of SARS-CoV-2 infection $(2.4 \%)$ is $1 / 4$ of that of SARS-CoV infection (9.6\%) (5,37).

Intriguingly, our meta-analysis found that GGOs were the dominant abnormal CT manifestation in pediatric COVID-19 cases. Moreover, mixed GGOs with consolidations, consolidations alone, pleural effusions, bronchopneumonia-like signs, air bronchograms, increased lung markings, white lung-like signs, lymphadenopathies were also included. Notably, the incidence of halo signs in pediatric COVID-19 cases was 26\%, which is rarely seen in adult COVID-19 cases (6). Pericardial effusions were found in the CT images of adult COVID-19 cases but were scarcely seen in the CT images of pediatric COVID-19 cases (6). Moreover, SARS-CoV-2 could infect any lung lobe, and the number of infected lobes was mostly one or two. Our meta-analysis also found that SARS-CoV-2 often infected lungs bilaterally in pediatric cases, while SARS$\mathrm{CoV}$ has been shown to infect lungs unilaterally. Therefore, our research helps in the early diagnosis, timely detection, and control of pediatric COVID-19 cases, which is very important for the development of regulatory measures and the control of COVID-19 spread (38).

The subgroup analyses showed that the summarized incidences of CT abnormalities of pediatric COVID-19 cases in Wuhan were higher than in the pediatric COVID-19 cases outside Wuhan. COVID-19 first attracted 
worldwide attention in Wuhan, causing Wuhan residents to be insufficiently aware of COVID-19 prevention. This lack of awareness resulted in a longer time interval between infection and medical treatment for Wuhan cases than for cases outside of Wuhan. Moreover, the heterogeneity among studies performed outside Wuhan was smaller than those performed in Wuhan, indicating that the research results outside of Wuhan were more stable than those in Wuhan. The pooled incidence of CT abnormalities from studies with a larger male-to-female ratio was higher, and the heterogeneity of studies with male-to-female ratios $\leq 1$ was smaller than that of studies with male-to-female ratios $>1$. These results indicated that the incidence of CT abnormalities was more stable in studies with smaller than larger male-to-female ratios. Additionally, the pooled incidence of CT abnormalities was higher in studies with $>20$ pediatric COVID-19 cases than in studies with 5-20 cases. The heterogeneity analyses indicated that the incidence of CT abnormalities was more stable in studies with 5-20 pediatric COVID-19 cases than in studies with $>20$ pediatric COVID-19 cases.

Children had relatively weak SARS-CoV-2 immune responses compared with adults. Angiotensin-converting enzyme 2 (ACE2) cell type expression also appears to be different between children and adults and has contributed to the milder clinical manifestations in children than adults with COVID-19 (15,23). COVID-19 causes pneumonia (fever, cough, and expectoration) and/or gastrointestinal abnormalities (diarrhea and vomiting). To explain these symptoms, a previous study showed that the SARS-CoV-2 envelope has glycoprotein protuberances that bind to ACE2, a protein receptor on epithelial cells of the nasopharynx, oral cavity, lungs, and gastrointestinal tract, among others (39). Once bound to ACE2, the virus can invade cells. Smoking increases the expression of ACE2, which leads to an increase in viruses that invade the cells (40).

This study found that $28 \%$ of pediatric confirmed cases were asymptomatic infections. In addition, asymptomatic infections also spread the SARS-CoV-2, bringing unprecedented difficulties to the prevention and control of COVID-19. It was found that children with negative RTPCR and asymptomatic infection have abnormal chest CT manifestations (8). Therefore, CT examinations are very important for the early diagnosis of COVID-19. However, not all countries have enough capacity to perform chest CT for COVID-19 cases. Exposure to family COVID-19 cases is the main way the SARS-CoV-2 infects children (41).
Among pediatric COVID-19 cases exposed to confirmed family cases, asymptomatic infections were also found (42). One of the reasons why there is currently no clustering transmission among children is because most countries chose to let children learn online at home rather than gather in school at the beginning of the outbreak.

Furthermore, although SARS-CoV and SARS-CoV-2 infections all increase pro-inflammatory cytokines, SARS$\mathrm{CoV}-2$ infections have a unique characteristic of inducing T-helper-2 type cytokine responses $(43,44)$. This unique trait holds significance for vaccine development. For example, Zhu et al. found that a candidate vaccine that expressed the SARS-CoV-2 protuberance glycoproteins; this vaccine showed promise in being able to stimulate both humoral and cellular responses against COVID-19 (44). However, the immune responses to SARS-CoV-2 infection in humans and the safety and immunogenicity of SARS$\mathrm{CoV}-2$ vaccines are currently uncertain and require further investigations.

Our research has several strengths. First, a metaanalysis of the various CT abnormalities in pediatric cases was performed and can be used as a reference to help clinicians diagnose COVID-19 in children. Second, a metaanalysis looking at lesion distributions was also conducted that helped to distinguish SARS-CoV and SARS-CoV-2 infections. Third, the articles included in our research were timely, with publications that spanned up to several months after the outbreak.

Our research also has several undeniable shortcomings. First, some completed yet unpublished articles that meet the inclusion criteria could generate additional data. Second, although articles were searched without region limitations, all included articles included were from China. Finally, the meta-analyses of several CT anomalies found that some articles had publication bias.

\section{Conclusions}

CT imaging of pediatric COVID-19 cases resulted in various abnormalities that were milder than those of adults. This study will hopefully provide a reference to help identify pediatric COVID-19 cases. Pediatric COVID-19 articles from other regions of the world are also needed to provide more comprehensive CT imaging results in children with COVID-19. More detailed and in-depth research on SARS-CoV-2 infection is also imperative, including research on immune response mechanisms and vaccine development. 


\section{Acknowledgments}

We thank BioMed Proofreading LLC for editing this manuscript.

Funding: This work was supported by the National Key R\&D Program of China (2017YFC0907405 to YHZ); the Liaoning Revitalization Talents Program (XLYC1802095 to YHZ); the Key R\&D Program of Liaoning Province (2019JH8/10300005 to YHZ); and the Science and Technology Project of Liaoning Province (2019JH6/10400002 to YHZ).

\section{Footnote}

Reporting Checklist: The authors have completed the PRISMA reporting checklist. Available at http://dx.doi. org/10.21037/tp-20-281

Peer Review File: Available at http://dx.doi.org/10.21037/tp20-281

Conflicts of Interest: All authors have completed the ICMJE uniform disclosure form (available at http://dx.doi. org/10.21037/tp-20-281). The authors have no conflicts of interest to declare.

Ethical Statement: The authors are accountable for all aspects of the work in ensuring that questions related to the accuracy or integrity of any part of the work are appropriately investigated and resolved.

Open Access Statement: This is an Open Access article distributed in accordance with the Creative Commons Attribution-NonCommercial-NoDerivs 4.0 International License (CC BY-NC-ND 4.0), which permits the noncommercial replication and distribution of the article with the strict proviso that no changes or edits are made and the original work is properly cited (including links to both the formal publication through the relevant DOI and the license). See: https://creativecommons.org/licenses/by-nc-nd/4.0/.

\section{References}

1. Manigandan S, Wu MT, Ponnusamy VK, et al. A systematic review on recent trends in transmission, diagnosis, prevention and imaging features of COVID-19. Process Biochem 2020;98:233-240.

2. Lu R, Zhao X, Li J, et al. Genomic characterisation and epidemiology of 2019 novel coronavirus: implications for virus origins and receptor binding. Lancet 2020;395:565-74.

3. World Health Organization (Internet). Coronavirus (COVID-19) outbreak (cited 2020 Jun 6). Available online: https://www.who.int/westernpacific/emergencies/covid-19

4. Mahmood A, Eqan M, Pervez S, et al. COVID-19 and frequent use of hand sanitizers; human health and environmental hazards by exposure pathways. Sci Total Environ 2020;742:140561.

5. World Health Organization (Internet). Coronavirus Disease (COVID-19) Dashboard (cited 2020 Aug 20). Available online: https://covid19.who.int/

6. Bao C, Liu X, Zhang H, et al. Coronavirus Disease 2019 (COVID-19) CT Findings: A Systematic Review and Meta-analysis. J Am Coll Radiol 2020;17:701-9.

7. The Children's Hospital of Philadelphia (Internet). News \& Views: COVID-19 and Kids - What Do We Know? (cited 2020 Nov 18). Available online: https://www.chop. edu/news/news-views-covid-19-and-kids-what-do-weknow

8. Liu M, Song Z, Xiao K. High resolution computed tomography manifestations. J Comput Assist Tomogr 2020;44:311-3.

9. Chen J, Zhang ZZ, Chen YK, et al. The clinical and immunological features of pediatric COVID-19 patients in China. Genes Dis 2020;7:535-41.

10. Feng K, Yun Y, Wang X, et al. Analysis of CT features of 15 Children with 2019 novel coronavirus infection 2020. Zhonghua Er Ke Za Zhi 2020;58:275-8.

11. National Heart, Lung, and Blood Institute (Internet). Study Quality Assessment Tools. (cited 2020 Jun 2). Available online: https://www.nhlbi.nih.gov/health-topics/ study-quality-assessment-tools

12. Li B, Shen J, Li L, et al. Radiographic and Clinical Features of Children with Coronavirus Disease (COVID-19) Pneumonia. Indian Pediatr 2020;57:423-6.

13. Li W, Cui H, Li K, et al. Chest computed tomography in children with COVID-19 respiratory infection. Pediatr Radiol 2020;50:796-9.

14. Lu Y, Wen H, Rong D, et al. Clinical characteristics and radiological features of children infected with the 2019 novel coronavirus. Clin Radiol 2020;75:520-5.

15. Ma H, Hu J, Tian J, et al. A single-center, retrospective study of COVID-19 features in children: a descriptive investigation. BMC Med 2020;18:123.

16. Ma YL, Xia SY, Wang M, et al. Clinical features of 
children with SARS-CoV-2 infection: an analysis of 115 cases. Zhongguo Dang Dai Er Ke Za Zhi 2020;22:290-3.

17. Qiu H, Wu J, Hong L, et al. Clinical and epidemiological features of 36 children with coronavirus disease 2019 (COVID-19) in Zhejiang, China: an observational cohort study. Lancet Infect Dis 2020;20:689-96.

18. Shen Q, Guo W, Guo T, et al. Novel coronavirus infection in children outside of Wuhan, China. Pediatr Pulmonol 2020;5 5:1424-9.

19. Song W, Li J, Zou N, et al. Clinical features of pediatric patients with coronavirus disease (COVID-19). J Clin Virol 2020;127:104377.

20. Steinberger S, Lin B, Bernheim A, et al. CT Features of Coronavirus Disease (COVID-19) in 30 Pediatric Patients. AJR Am J Roentgenol 2020;215:1303-11.

21. Su L, Ma X, Yu H, et al. The different clinical characteristics of corona virus disease cases between children and their families in China - the character of children with COVID-19. Emerg Microbes Infect 2020;9:707-13.

22. Sun D, Li H, Lu XX, et al. Clinical features of severe pediatric patients with coronavirus disease 2019 in Wuhan: a single center's observational study. World J Pediatr 2020;16:251.

23. Tan X, Huang J, Zhao F, et al. Clinical features of children with SARS-CoV-2 infection: an analysis of 13 cases from Changsha, China. Zhongguo Dang Dai Er Ke Za Zhi. 2020;22:294-8.

24. Tan YP, Tan BY, Pan J, et al. Epidemiologic and clinical characteristics of 10 children with coronavirus disease 2019 in Changsha, China. J Clin Virol 2020;127:104353.

25. Wang D, Ju XL, Xie F, et al. Clinical analysis of 31 cases of 2019 novel coronavirus infection in children from six provinces (autonomous region) of northern China. Zhonghua Er Ke Za Zhi 2020;58:269-74.

26. Wu HP, Li BF, Chen X, et al. Clinical features of coronavirus disease 2019 in children aged $<18$ years in Jiangxi, China: an analysis of 23 cases. Zhongguo Dang Dai Er Ke Za Zhi 2020;22:419-24.

27. Xia W, Shao J, Guo Y, et al. Clinical and CT features in pediatric patients with COVID-19 infection: Different points from adults. Pediatr Pulmonol 2020;55:1169-74.

28. Zheng F, Liao C, Fan QH, et al. Clinical Characteristics of Children with Coronavirus Disease 2019 in Hubei, China. Curr Med Sci 2020;40:275-80.

29. Zhong Z, Xie X, Huang W, et al. Chest CT findings and clinical features of coronavirus disease 2019 in children.
Zhong Nan Da Xue Xue Bao Yi Xue Ban 2020;45:236-42.

30. Zhou Y, Yang GD, Feng K, et al. Clinical features and chest CT findings of coronavirus disease 2019 in infants and young children. Zhongguo Dang Dai Er Ke Za Zhi 2020;22:215-20.

31. Zhu L, Wang J, Huang R, et al. Clinical characteristics of a case series of children with coronavirus disease 2019. Pediatr Pulmonol 2020;55:1430-2.

32. Chung M, Bernheim A, Mei X, et al. CT Imaging features of 2019 novel coronavirus (2019-nCoV). Radiology 2020;295:202-7.

33. Lu X, Zhang L, Du H, et al. SARS-CoV-2 infection in children. N Engl J Med 2020;382:1663-5.

34. Wu Z, McGoogan JM. Characteristics of and important lessons from the coronavirus disease 2019 (COVID-19) outbreak in china: summary of a report of 72314 cases from the Chinese center for disease control and prevention. JAMA 2020;323:1239-42.

35. Chang TH, Wu JL, Chang LY. Clinical characteristics and diagnostic challenges of pediatric COVID-19: A systematic review and meta-analysis. J Formos Med Assoc 2020;119:982-9.

36. Wang D, Hu B, Hu C, et al. Clinical characteristics of 138 hospitalized patients with 2019 novel coronavirus-infected pneumonia in Wuhan, China. JAMA 2020;323:1061-9.

37. World Health Organization (Internet). Summary of probable SARS cases with onset of illness from 1 November 2002 to 31 July 2003 (cited 2020 Jun 6). Available online: https://www. who.int/csr/sars/country/ table2004_04_21/en/

38. Li Z, Chen Q, Feng L, et al. Active case finding with case management: the key to tackling the COVID-19 pandemic. Lancet 2020;396:63-70.

39. Yan R, Zhang Y, Li Y, et al. Structural basis for the recognition of SARS-CoV-2 by full-length human ACE2. Science 2020;367:1444-8.

40. Saheb Sharif-Askari N, Saheb SF, Alabed M, et al. Airways Expression of SARS-CoV-2 Receptor, ACE2, and TMPRSS2 Is Lower in Children Than Adults and Increases with Smoking and COPD. Mol Ther Methods Clin Dev 2020;18:1-6.

41. Chan JF, Yuan S, Kok KH, et al. A familial cluster of pneumonia associated with the 2019 novel coronavirus indicating person-to-person transmission: a study of a family cluster. Lancet 2020;395:514e23.

42. Bai Y, Yao L, Wei T, et al. Presumed Asymptomatic Carrier Transmission of COVID-19. JAMA 2020;323:1406-7. 
43. Mahallawi WH, Khabour OF, Zhang Q, et al. MERS-CoV infection in humans is associated with a pro-inflammatory Th1 and Th17 cytokine profile. Cytokine 2018;104:8-13. 44. Zhu FC, Li YH, Guan XH, et al. Safety, tolerability,

Cite this article as: Zang ST, Han X, Cui Q, Chang Q, $\mathrm{Wu}$ QJ, Zhao YH. Imaging characteristics of coronavirus disease 2019 (COVID-19) in pediatric cases: a systematic review and meta-analysis. Transl Pediatr 2021;10(1):1-16. doi: $10.21037 /$ tp-20-281 and immunogenicity of a recombinant adenovirus type5 vectored COVID-19 vaccine: a dose-escalation, openlabel, non-randomised, first-in-human trial. Lancet 2020;395:1845-54. 


\section{Supplementary material}

\section{Abbreviation:}

COVID-19 = coronavirus disease 2019; CT = computed tomography; GGO = ground-glass opacity.

\section{Contents}

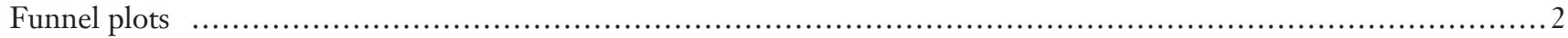

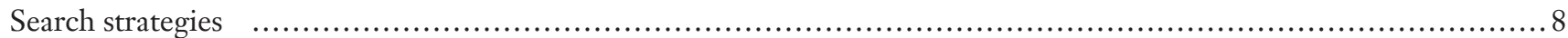

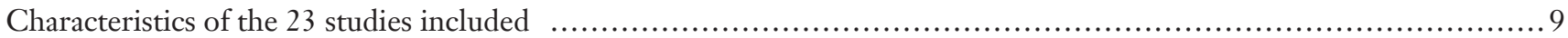

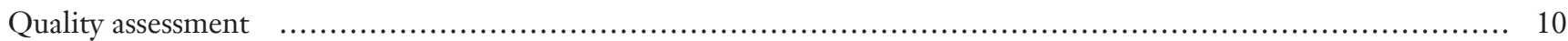

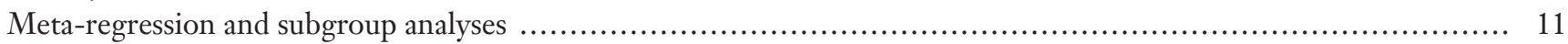

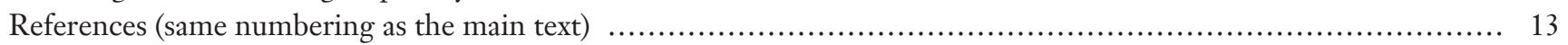




\section{Funnel plots}

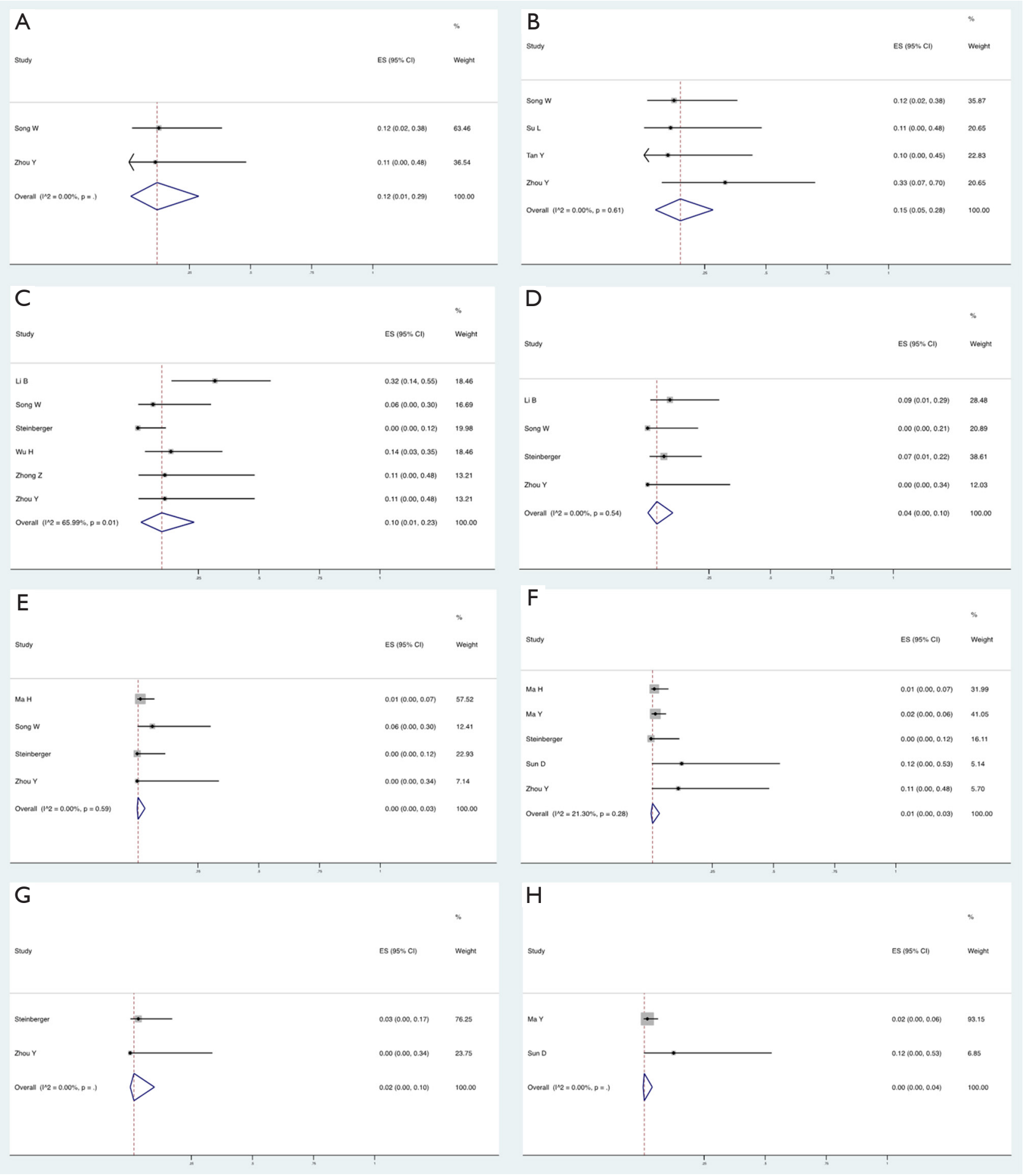

Supplementary figure 1. Forest plots of the incidence of abnormal CT findings in pediatric COVID-19 cases. The solid diamond and the corresponding line represent effect size (ES) and 95\% confidence interval (CI) of each article. The bottom diamond represents the summarized incidence of abnormal CT finding. The incidences of (A) air bronchogram, (B) bronchopneumonia-like sign, (C) consolidation, (D) crazy paving sign, (E) lymphadenopathy, (F) pleural effusion, $(\mathrm{G})$ reverse halo sign, and (H) white lung-like sign were $12 \%(95 \%$ CI: 1\%-29\%), 15\% (95\% CI: 5\%-28\%), 10\% (95\% CI: 1\%-23\%),4\% (95\% CI: 0-10\%), 0 (95\% CI: 0-3\%), 1\% (95\% CI: 0-3\%), 2\% (95\% CI: $0-10 \%$ ), and 0 (95\% CI: 0-4\%), respectively. 
A

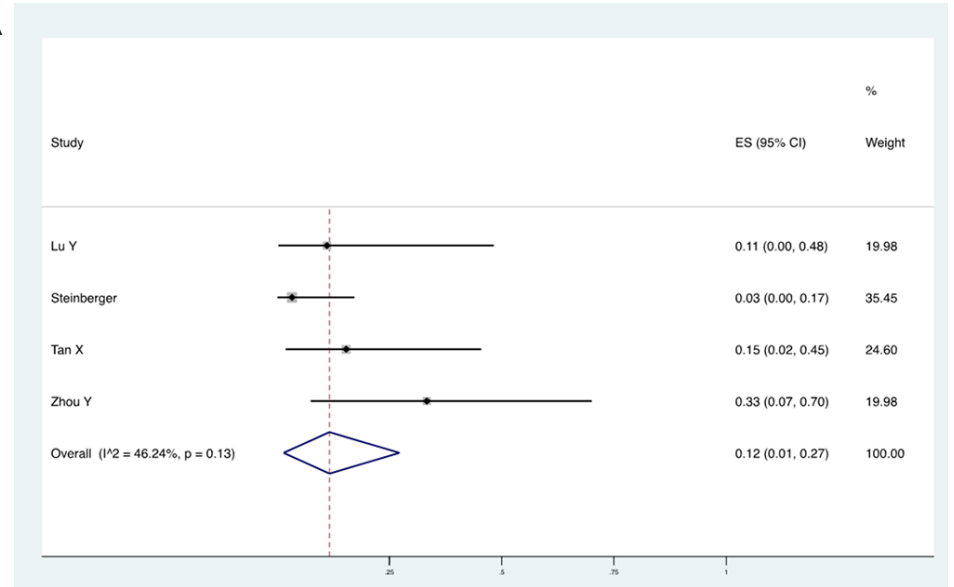

B

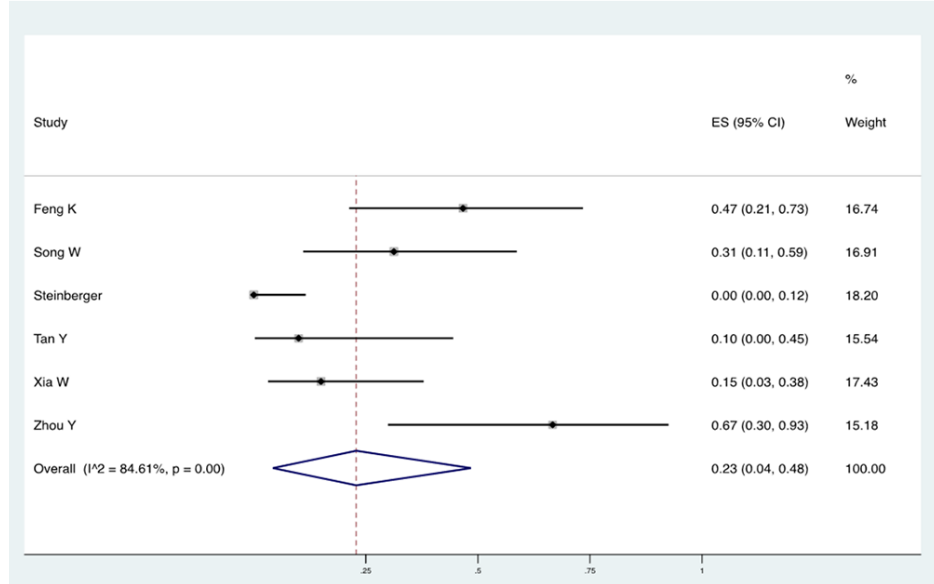

C

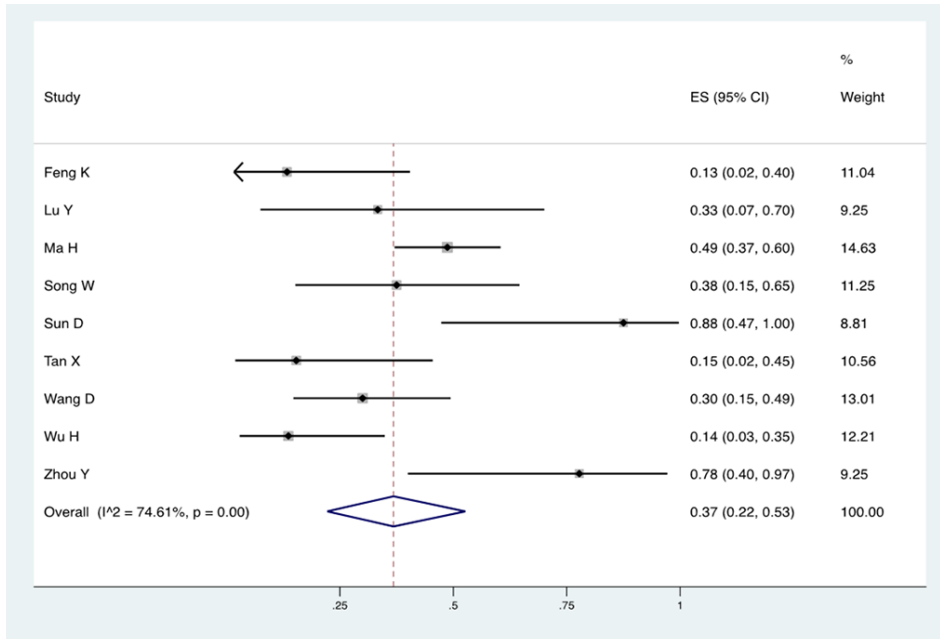

Supplementary Figure 2. Forest plots of the incidence of lesions of different shapes shown on CT images in pediatric COVID-19 cases. The solid diamond and the corresponding line represent effect size (ES) and $95 \%$ confidence interval (CI) of each article. The bottom diamond represents the summarized incidence of abnormal CT finding. The incidences of (A) linear lesion, (B) nodular lesion, and (C) patchy lesion were $12 \%$ (95\% CI: 1\%-27\%), 23\% (95\% CI: 4\%-48\%), and 37 (95\% CI: $22-53 \%$ ). 


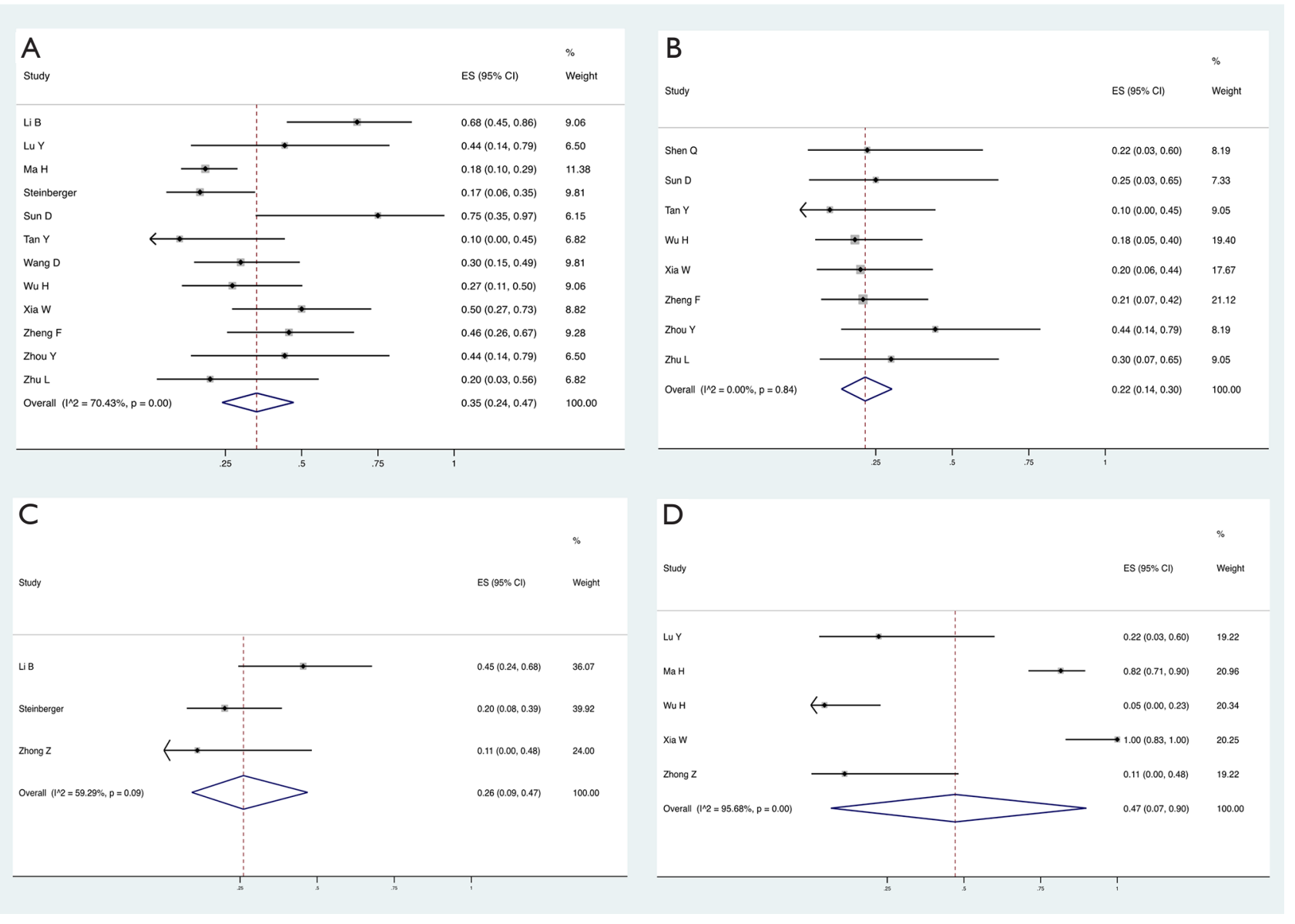

Supplementary Figure 3. Forest plots of the incidence of lesion distribution shown on CT images in pediatric COVID-19 cases. The solid diamond and the corresponding line represent effect size (ES) and 95\% confidence interval (CI) of each article. The bottom diamond represents the summarized incidence of abnormal CT finding. The incidences of (A) bilateral lesion, (B) unilateral lesion, (C) peripheral lesion, and (D) subpleural lesion were 35\% (95\% CI: 24\%-47\%), 22\% (95\% CI: 14\%-30\%), 26\% (95\% CI: 9\%-47\%), and 47\% (95\% CI: 7\%-90\%), respectively. 

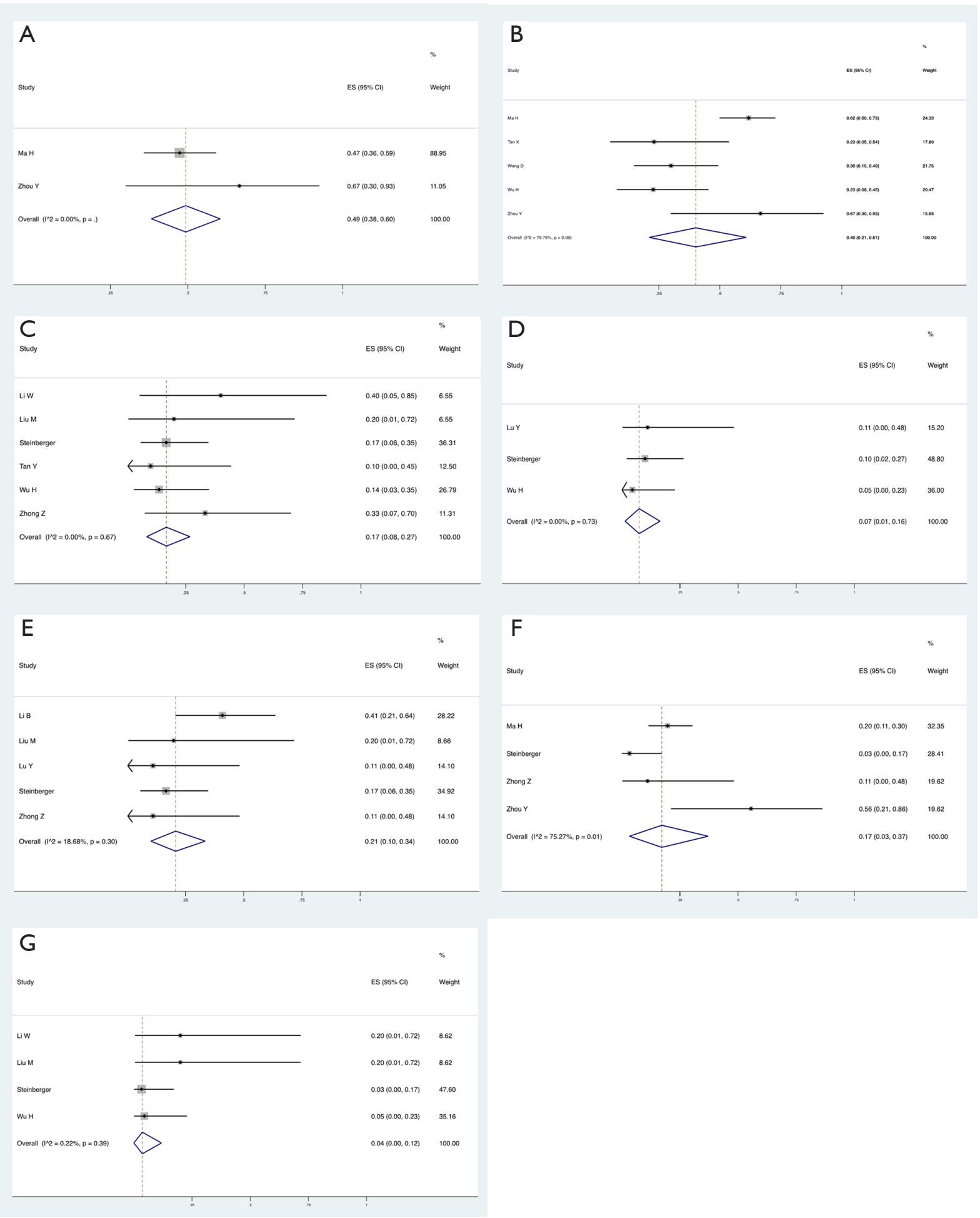

Supplementary Figure 4. Forest plots of the incidence of infection in each lobe shown on CT images in pediatric COVID-19 cases. The solid diamond and the corresponding line represent effect size (ES) and 95\% confidence interval (CI) of each article. The bottom diamond represents the summarized incidence. The incidences of (A)upper lobe infection, (B) lower lobe infection, (C)left lower lobe infection, (D) left upper lobe infection, (E) right lower lobe infection, (F) middle lobe infection, right upper lobe infection were 49\% (95\% CI: 38\%-60\%), 40\% (95\% CI: 21\%-61\%), 17\% (95\% CI: 8\%-27\%),7\% (95\% CI: 1\%-16\%) and 21\% (95\% CI: 10\%-34\%), 17\% (95\% CI: 3\%-37\%), 4\% (95\% CI: $0 \%-12 \%)$, respectively. 


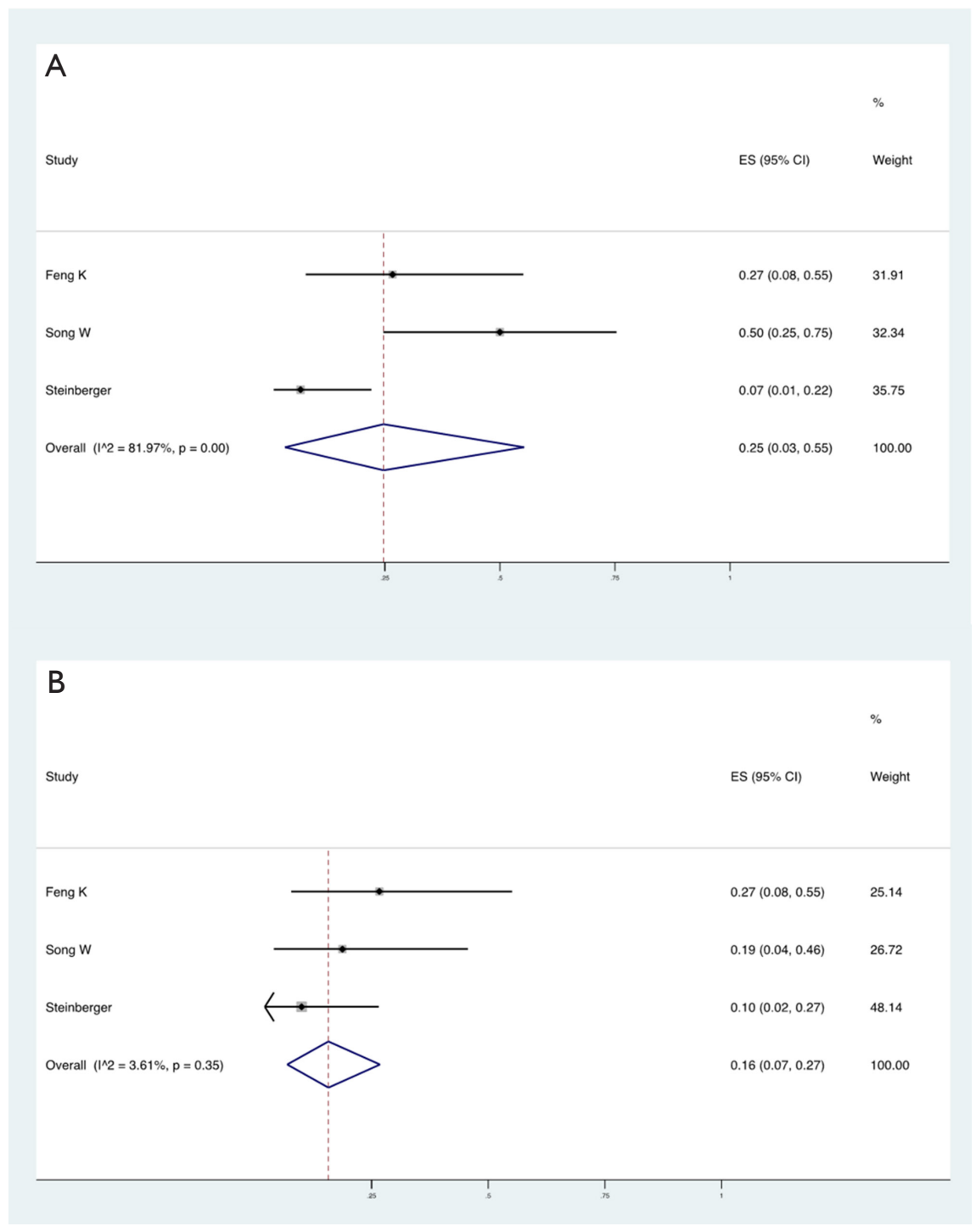

Supplementary Figure 5. Forest plots of the incidence of the number of infected lobes shown on CT images in pediatric COVID-19 cases. The solid diamond and the corresponding line represent effect size (ES) and $95 \%$ confidence interval (CI) of each article. The bottom diamond represents the summarized incidence. The incidences of (A) one infected lobe, and (B) two-lobe were $25 \%$ (95\% CI: 3\%-55\%), and $16 \%$ (95\% CI: 7\%-27\%), respectively. 


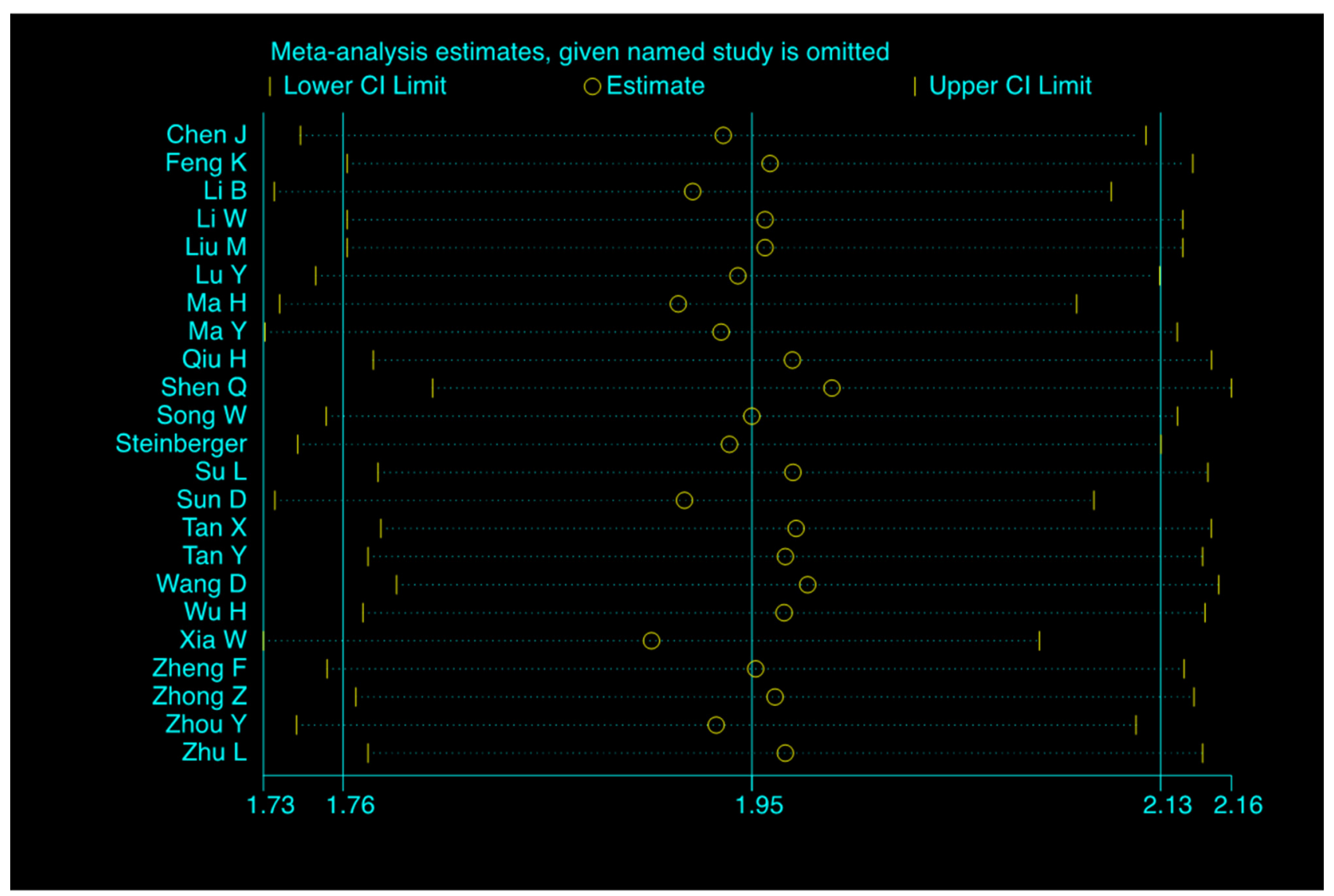

Supplementary Figure 6. Sensitivity analysis. It shows that each single included study does not affect the summarized incidence of CT abnormalities in pediatric COVID-19 cases. 


\section{Search strategies}

Table 1. Search strategies for imaging characteristics of COVID-19 in pediatric cases

\begin{tabular}{|c|c|c|}
\hline Database & Query & Items Found \\
\hline $\begin{array}{l}\text { Web of } \\
\text { Science }^{\ddagger}\end{array}$ & $\begin{array}{l}\text { TS }=((\text { Child OR Children OR Infant OR Infants OR Newborn OR Newborns OR Neonate OR Neo } \\
\text { nates OR pediatric) and ((Beam Tomography, Electron) OR Chest OR (Cine-CT) OR (Computed } \\
\text { Tomography) OR (Computer Assisted Tomography) OR (Computerized Tomography) OR CT O } \\
\mathrm{R} \text { (Electron Beam Tomography) OR Image OR Images OR Imaging OR Radiographic OR Radio } \\
\text { graphy OR Radiology OR Roentgenography OR Tomodensitometry OR (Tomography, Electron } \\
\text { Beam) OR (Tomography, Transmission Computed) OR (Transmission Computed Tomography) OR (X } \\
\text { Ray) OR (X Rays) OR Xray OR (X-Ray) OR (X-Rays)) and ((2019 nCoV) OR 2019nCoV OR (2019- } \\
\text { nCoV) OR (2019 novel coronavirus) OR (coronavirus disease 2019) OR (coronavirus } \\
\text { disease-19) OR (COVID 19) OR COVID19 OR (new coronavirus) OR (novel coronavirus) OR (SARS } \\
\text { CoV-2) OR (SARS-CoV-2) OR (severe acute respiratory syndrome coronavirus } 2) \text { OR (Wuhan AND c } \\
\text { oronavirus))) }\end{array}$ & 260 \\
\hline
\end{tabular}

Abbreviation: COVID-19 = coronavirus disease 2019; CT = computed tomography; SARS-CoV-2 = severe acute respiratory syndrome coronavirus 2; TS = Theme Subject.

${ }^{\dagger}$ PubMed database is available from https://www.ncbi.nlm.nih.gov/pubmed.

${ }^{\ddagger}$ Web of Science database website is available from https://www.webofknowledge.com.

${ }^{\S}$ The Cochrane Library database is available from https://www.cochranelibrary.com/. 


\section{Characteristics of the 23 studies included}

Table 2 Characteristics of the 23 studies included in the review and meta-analysis on chest imaging of pediatric COVID-19 cases

\begin{tabular}{|c|c|c|c|c|c|}
\hline Study & City, province/autonomous region/municipality, country & Design & Diagnostic criteria for COVID-19 & Duration & $\begin{array}{l}\text { Epidemiological } \\
\text { history (exposure } \\
\text { to confirmed } \\
\text { or suspected } \\
\text { COVID-19/Wuhan/ } \\
\text { both/uncertain }\end{array}$ \\
\hline Chen J & Chongqing, China & Case series & 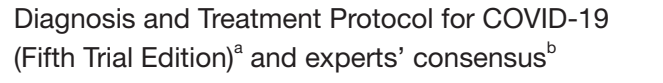 & $\begin{array}{l}\text { January } 28 \text { to } \\
\text { February } 11,2020\end{array}$ & $8 / 4 / 0 / 0$ \\
\hline Feng $\mathrm{K}$ & Shenzhen, Guangdong, China & Case series & $\begin{array}{l}\text { Diagnosis and Treatment Protocol for COVID-19 } \\
\text { (Fifth Revised Edition) }^{c}\end{array}$ & $\begin{array}{l}\text { January } 16 \text { to } \\
\text { February } 6,2020\end{array}$ & $12 / 3 / 0 / 0$ \\
\hline Li B & Yichang, Hubei, China & Case series & Positive SARS-CoV-2 nucleic acid test result & $\begin{array}{l}\text { January } 16 \text { to March } \\
14,2020\end{array}$ & $0 / 0 / 0 / 22$ \\
\hline Li W & Zhuhai, Guangdong, China & Case series & Positive SARS-CoV-2 nucleic acid test result & $\begin{array}{l}\text { January } 28 \text { to } \\
\text { February } 8,2020\end{array}$ & $4 / 1 / 0 / 0$ \\
\hline Liu M & Chongqing, China & Case report & NR & NR & $4 / 0 / 0 / 1$ \\
\hline LuY & Guangzhou, Guangdong, China & Case series & Positive SARS-CoV-2 nucleic acid test result & $\begin{array}{l}\text { January } 22 \text { to } \\
\text { February } 9,2020\end{array}$ & $2 / 4 / 3 / 0$ \\
\hline $\mathrm{MaH}$ & Wuhan, Hubei, China & Case series & Positive SARS-CoV-2 nucleic acid test result & $\begin{array}{l}\text { January } 21 \text { to } \\
\text { February } 14,2020\end{array}$ & NR \\
\hline MaY & Wuhan, Hubei, China & Case series & $\begin{array}{l}\text { Diagnosis and Treatment Protocol for COVID-19 } \\
\text { (Sixth Trial Edition) }^{d}\end{array}$ & NR & $0 / 10 / 105 / 0$ \\
\hline Qiu H & Ningbo and Wenzhou, Zhejiang, China & Cohort & Positive SARS-CoV-2 nucleic acid test & $\begin{array}{l}\text { January } 17 \text { to March } \\
1,2020\end{array}$ & $24 / 4 / 8 / 0$ \\
\hline Shen Q & Changsha, Hunan, China & Case series & NR & $\begin{array}{l}\text { January } 30 \text { to } \\
\text { February } 26,2020\end{array}$ & $6 / 2 / 0 / 1$ \\
\hline Song W & Xiangyang, Hubei, China & Case series & $\begin{array}{l}\text { Diagnosis and treatment recommendation for } \\
\text { pediatric coronavirus disease-19 (Second Edition) }\end{array}$ & $\begin{array}{l}\text { January } 1 \text { to March } \\
17,2020\end{array}$ & $14 / 1 / 0 / 1$ \\
\hline Steinberger & $\begin{array}{l}\text { Bozhou, Anhui; Chengdu, Sichuan; Hangzhou, Ruian, } \\
\text { Zhejiang; Guilin, Guangxi; Zhuhai, Guangdong; China }\end{array}$ & Case series & Positive SARS-CoV-2 nucleic acid test result & $\begin{array}{l}\text { January } 23 \text { to } \\
\text { February } 8,2020\end{array}$ & $26 / 3 / 0 / 1$ \\
\hline Su L & Jinan, Shandong, China & Case series & Positive SARS-CoV-2 nucleic acid test result & $\begin{array}{l}\text { January } 24 \text { to } \\
\text { February } 24,2020\end{array}$ & $9 / 0 / 0 / 0$ \\
\hline Sun D & Wuhan, Hubei, China & Case series & $\begin{array}{l}\text { Diagnosis and Treatment Protocol for COVID-19 } \\
\text { (Sixth Trial Edition) }^{d}\end{array}$ & $\begin{array}{l}\text { January } 24 \text { to } \\
\text { February } 24,2020\end{array}$ & $0 / 1 / 5 / 2$ \\
\hline $\operatorname{Tan} \mathrm{X}$ & Changsha, Hunan, China & Case series & $\begin{array}{l}\text { Diagnosis and Treatment Protocol for COVID-19 } \\
\text { (Sixth Trial Edition) }^{\mathrm{d}}\end{array}$ & $\begin{array}{l}\text { January } 17 \text { to } \\
\text { February } 29,2020\end{array}$ & $10 / 0 / 3 / 0$ \\
\hline $\operatorname{Tan} Y$ & Changsha, Hunan, China & Case series & $\begin{array}{l}\text { Diagnosis and Treatment Protocol for COVID-19 } \\
\text { (Sixth Trial Edition) }^{d}\end{array}$ & $\begin{array}{l}\text { January } 27 \text { to March } \\
10,2020\end{array}$ & $7 / 3 / 0 / 0$ \\
\hline Wang D & $\begin{array}{l}\text { Shaanxi, Gansu, Ningxia, Hebei, Henan, Shandong, } \\
\text { China }\end{array}$ & Case series & $\begin{array}{l}\text { Positive SARS-CoV-2 nucleic acid test and expert } \\
\text { consultation }\end{array}$ & $\begin{array}{l}\text { January } 25 \text { to } \\
\text { February } 21,2020\end{array}$ & $22 / 9 / 0 / 0$ \\
\hline Wu H & $\begin{array}{l}\text { Ganzhou, Nanchang, Yichun, Shangrao, Jiujiang, Fuzhou, } \\
\text { and Pingxiang; Jiangxi, China }\end{array}$ & Case series & $\begin{array}{l}\text { Diagnosis and Treatment Protocol for COVID-19 } \\
\text { (Seventh Trial Edition) }{ }^{f} \text { and Diagnosis and treatment } \\
\text { of COVID-19 in children in Hubei (Trial version } 1)^{9}\end{array}$ & $\begin{array}{l}\text { January } 27 \text { to March } \\
4,2020\end{array}$ & 16/NR/NR/0 \\
\hline Xia W & Wuhan, Hubei, China & Case series & $\begin{array}{l}\text { Diagnosis and Treatment Protocol for COVID-19 } \\
\text { (Fifth Revised Edition) }^{c}\end{array}$ & $\begin{array}{l}\text { January } 23 \text { to } \\
\text { February } 8,2020\end{array}$ & $13 / 0 / 0 / 7$ \\
\hline Zheng $\mathrm{F}$ & Wuhan, Hubei, China & Case series & $\begin{array}{l}\text { Diagnosis and treatment of COVID-19 in children in } \\
\text { Hubei (Trial version } 1)^{g}\end{array}$ & $\begin{array}{l}\text { February } 1 \text { to } \\
\text { February } 10,2020\end{array}$ & $0 / 5 / 16 / 4$ \\
\hline Zhong Z & Changsha, Hunan, China & Case series & $\begin{array}{l}\text { Positive SARS-CoV-2 nucleic acid test result or } \\
\text { SARS-CoV-2 gene sequencing }\end{array}$ & NR & $9 / 0 / 0 / 0$ \\
\hline Zhou Y & Shenzhen, Guangdong, China & Case series & $\begin{array}{l}\text { Diagnosis and Treatment Protocol for COVID-19 } \\
\text { (Sixth Trial Edition) }^{\mathrm{d}}\end{array}$ & $\begin{array}{l}\text { January } 20 \text { to } \\
\text { February } 10,2020\end{array}$ & $6 / 0 / 3 / 0$ \\
\hline Zhu L & Three cities, Jiangsu, China & Case series & Positive SARS-CoV-2 nucleic acid test result & $\begin{array}{l}\text { January } 24 \text { to } \\
\text { February } 22,2020\end{array}$ & $7 / 3 / 0 / 0$ \\
\hline
\end{tabular}

COVID-19, coronavirus disease 2019, CT, computed tomography, GGO, ground-glass opacity, NR, not report, SARS-CoV-2, severe acute respiratory syndrome coronavirus 2.

a. Available from http://www.nhc.gov.cn/yzygj/s7653p/202002/3b09b894ac9b4204a79db5b8912d4440/files/7260301a393845fc87fcf6dd52965ecb.pdf.

b. Available from https://doi.org/10.1007/s12519-020-00343-7.

c. Available from http://www.nhc.gov.cn/yzygj/s7653p/202002/d4b895337e19445f8d728fcaf1e3e13a/files/ab6bec7f93e64e7f998d802991203cd6.pdf.

d. Available from http://www.nhc.gov.cn/yzygj/s7653p/202002/8334a8326dd94d329df351d7da8aefc2/files/b218cfeb1bc54639af227f922bf6b817.pdf.

e. Available from http://kns.cnki.net/ kcms/detail/33.1248.R.20200225.1518.002.html.

f. Available from http://www.nhc.gov.cn/yzygj/s7653p/202003/46c9294a7dfe4cef80dc7f5912eb1989/files/ce3e6945832a438eaae415350a8ce964.pdf.

g. Available from http://www.zgddek.com/CN/10.7499/j.issn.1008-8830.2020.02.003\#. 


\section{Quality assessment}

Table 3 Quality assessment of case series studies included in the meta-analysis'

\begin{tabular}{|c|c|c|c|c|c|c|c|c|c|c|c|c|c|c|c|c|c|c|c|c|c|c|}
\hline Criteria & Chen J & Feng $\mathrm{K}$ & Li B & LiW & Liu M & LuY & Ma H & MaY & Shen $Q$ & Song $\mathrm{W}$ & Steinberger & Su L & Sun D & $\operatorname{Tan} \mathrm{X}$ & $\operatorname{Tan} \mathrm{Y}$ & Wang $\mathrm{D}$ & WuH & Xia W & Zheng $\mathrm{F}$ & Zhong Z & Zhou Y & Zhu L \\
\hline $\begin{array}{l}\text { 1. Was the study question or objective } \\
\text { clearly stated? }\end{array}$ & Yes & Yes & Yes & Yes & Yes & Yes & Yes & Yes & Yes & Yes & Yes & Yes & Yes & Yes & Yes & Yes & Yes & Yes & Yes & Yes & Yes & Yes \\
\hline $\begin{array}{l}\text { 2. Was the study population clearly } \\
\text { and fully described, including a case } \\
\text { definition? }\end{array}$ & Yes & Yes & Yes & Yes & No & Yes & Yes & Yes & No & Yes & Yes & No & Yes & Yes & Yes & Yes & Yes & Yes & Yes & Yes & Yes & Yes \\
\hline 3. Were the cases consecutive? & No & Yes & Yes & Yes & Yes & Yes & Yes & Yes & Yes & Yes & No & Yes & Yes & Yes & Yes & Yes & No & Yes & Yes & No & Yes & Yes \\
\hline 4. Were the subjects comparable? & No & No & No & No & No & No & No & No & No & No & No & No & No & No & No & No & No & No & No & No & No & No \\
\hline $\begin{array}{l}\text { 5. Were the outcome measures clearly } \\
\text { defined, valid, reliable, and implemented } \\
\text { consistently across all study participants? }\end{array}$ & Yes & Yes & Yes & Yes & Yes & Yes & Yes & Yes & Yes & Yes & Yes & Yes & Yes & Yes & Yes & Yes & Yes & Yes & Yes & Yes & Yes & Yes \\
\hline 6. Was the length of follow-up adequate? & Yes & Yes & Yes & Yes & NR & Yes & Yes & NR & Yes & Yes & Yes & Yes & Yes & Yes & Yes & Yes & Yes & Yes & Yes & NR & Yes & Yes \\
\hline $\begin{array}{l}\text { 7. Were the statistical methods well- } \\
\text { described? }\end{array}$ & Yes & Yes & No & Yes & No & No & Yes & Yes & No & No & Yes & Yes & No & No & Yes & Yes & Yes & No & Yes & No & No & No \\
\hline 8. Were the results well-described? & Yes & Yes & Yes & No & Yes & Yes & Yes & Yes & Yes & Yse & Yes & Yes & Yes & Yes & Yes & Yes & Yes & No & Yes & Yes & Yes & Yes \\
\hline The number of positive answers & 7 & 7 & 6 & 6 & 4 & 6 & 6 & 6 & 5 & 5 & 6 & 6 & 6 & 6 & 7 & 7 & 6 & 5 & 7 & 4 & 6 & 6 \\
\hline Quality Rating $^{\ddagger}$ & Good & Good & Fair & Fair & Fair & Fair & Good & Fair & Fair & Fair & Good & Fair & Fair & Fair & Good & Good & Good & Fair & Good & Fair & Fair & Fair \\
\hline
\end{tabular}

NR, not reported.
${ }^{\dagger}$ Quality assessment tool for case series studies is available from https://www.nhlbi.nih.gov/health-topics/study-quality-assessment-tools, provided by National Heart, Lung, and Blood Institute.

Quality assessment tool for case series studies is avaliable from hittps:/Mww.nhibi.nin.gov/health-topics/study-quality-assessment-tools, provide
tPositive answers from zero to three, four to six, and seven to eight indicate poor, fair, and good quality of the studies evaluated, respectively.

Table 4 Quality assessment of cohort study included in the meta-analysis

1. Was the research question or objective in this paper clearly stated?

Qiu [35]

2. Was the study population clearly specified and defined?

3. Was the participation rate of eligible persons at least $50 \%$ ?

4. Were all the subjects selected or recruited from the same or similar populations (including the same time period)?

5. Were inclusion and exclusion criteria for being in the study prespecified and applied uniformly to all participants?

6. Was a sample size justification, power description, or variance and effect estimates provided?

7. Were the exposure measures (dependent variables) clearly defined, valid, reliable, and implemented consistently across all study participants?

8. Were the outcome measures (dependent variables) clearly defined, valid, reliable, and implemented consistently across all study participants?

10. Were key potential confounding variables measured and adjusted statistically for their impact on the relationship between exposure(s) and outcome(s)?

The number of positive answers

Quality Rating ${ }^{\ddagger}$

Yes

Yes

Yes

Yes

Yes

Yes

Yes

Yes

No

${ }^{t}$ Definitions/explanations for each item of quality assessment tool for observational cohort studies is available from https://www.nhlbi.nih.gov/health-topics/study-quality-assessment-tools, and is provided by National Heart, Lung, and Blood Institute.

Positive answers from zero to three, from four to six, and from seven to nine indicate poor, fair, and good quality of the studies evaluated, respectively. 


\section{Meta-regression and subgroup analyses}

Table 5 Meta-regression and subgroup analyses on CT abnormalities in pediatric COVID-19 cases

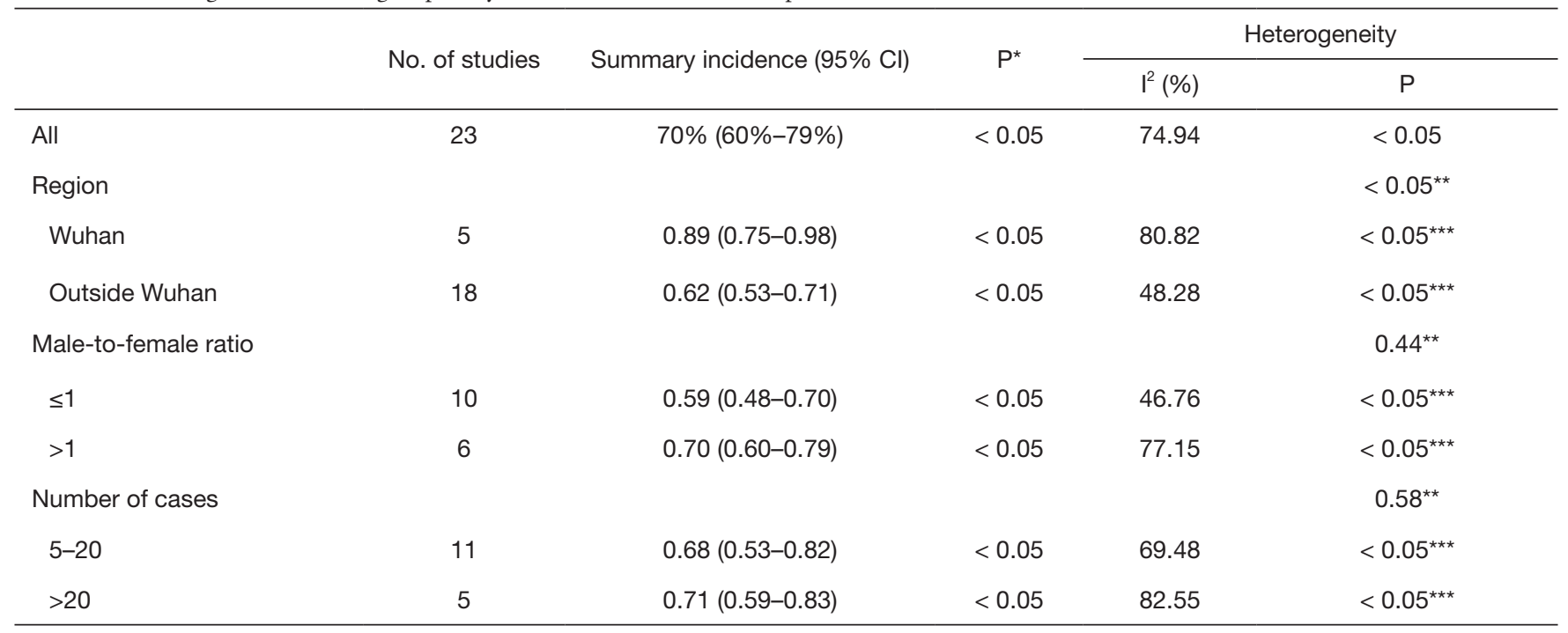

Abbreviations: $\mathrm{Cl}=$ confidence interval; COVID-19 = coronavirus disease 2019; $\mathrm{CT}$ = computed tomography.

${ }^{*}$ Significance of summarized incidences.

**Significance of meta-regression on possible sources of heterogeneity.

*** Significance of subgroup analysis on possible sources of heterogeneity.

$P<0.05$ was regarded as indication of statistical significance.

Table 6 Meta-regression and subgroup analyses on GGO incidence in pediatric COVID-19 cases

\begin{tabular}{|c|c|c|c|c|c|}
\hline & No. of studies & Summary incidence $(95 \% \mathrm{Cl})$ & $\mathrm{P}^{*}$ & \multicolumn{2}{|c|}{ Heterogeneity } \\
\hline All & 17 & $0.40(0.29-0.51)$ & $<0.05$ & 66.90 & $<0.05$ \\
\hline Region & & & & & $<0.05^{\star \star}$ \\
\hline Wuhan & 2 & $0.67(0.56-0.78)$ & $<0.05$ & NA & NA \\
\hline Male-to-female ratio & & & & & $0.40^{\star *}$ \\
\hline$\leq 1$ & 9 & $0.33(0.22-0.45)$ & $<0.05$ & 40.05 & $0.10^{\star \star \star}$ \\
\hline$>1$ & 8 & $0.49(0.32-0.65)$ & $<0.05$ & 69.71 & $<0.05^{\star \star \star}$ \\
\hline Number of cases & & & & & $0.35^{\star *}$ \\
\hline
\end{tabular}

Abbreviations: $\mathrm{Cl}$ = confidence interval; COVID-19 = coronavirus disease 2019; CT = computed tomography; GGO = ground-glass opacity; NA = not available.

*Significance of summarized incidences.

**Significance of meta-regression on possible sources of heterogeneity.

\$Significance of subgroup analysis on possible sources of heterogeneity.

$\mathrm{P}<0.05$ was regarded as indication of statistical significance. 
Table 7 Meta-regression and subgroup analyses on the incidence of patchy lesions in pediatric COVID-19 cases

\begin{tabular}{|c|c|c|c|c|c|}
\hline & No. of studies & Summary incidence $(95 \% \mathrm{Cl})$ & $\mathrm{P}^{*}$ & \multicolumn{2}{|c|}{ Heterogeneity } \\
\hline All & 9 & $0.37(0.22-0.53)$ & $<0.05$ & 74.61 & $<0.05$ \\
\hline Region & & & & & $0.28^{\star *}$ \\
\hline Wuhan & 2 & $0.53(0.41-0.64)$ & $<0.05$ & NA & NA \\
\hline Male-to-female ratio & & & & & $0.93^{\star *}$ \\
\hline$\leq 1$ & 6 & $0.27(0.13-0.45)$ & $<0.05$ & 64.12 & $<0.05^{\star \star \star}$ \\
\hline$>1$ & 3 & $0.54(0.32-0.76)$ & $<0.05$ & NA & NA \\
\hline Number of cases & & & & & $0.32^{\star \star}$ \\
\hline
\end{tabular}

Abbreviations: $\mathrm{Cl}=$ confidence interval; COVID-19 = coronavirus disease 2019; NA = not available.

*Significance of summarized incidences.

${ }^{*}$ Significance of meta-regression on possible sources of heterogeneity.

${ }^{* \star *}$ Significance of subgroup analysis on possible sources of heterogeneity.

$\mathrm{P}<0.05$ was regarded as indication of statistical significance.

Table 8 Meta-regression and subgroup analyses on the incidence of bilateral lesions in pediatric COVID-19 cases

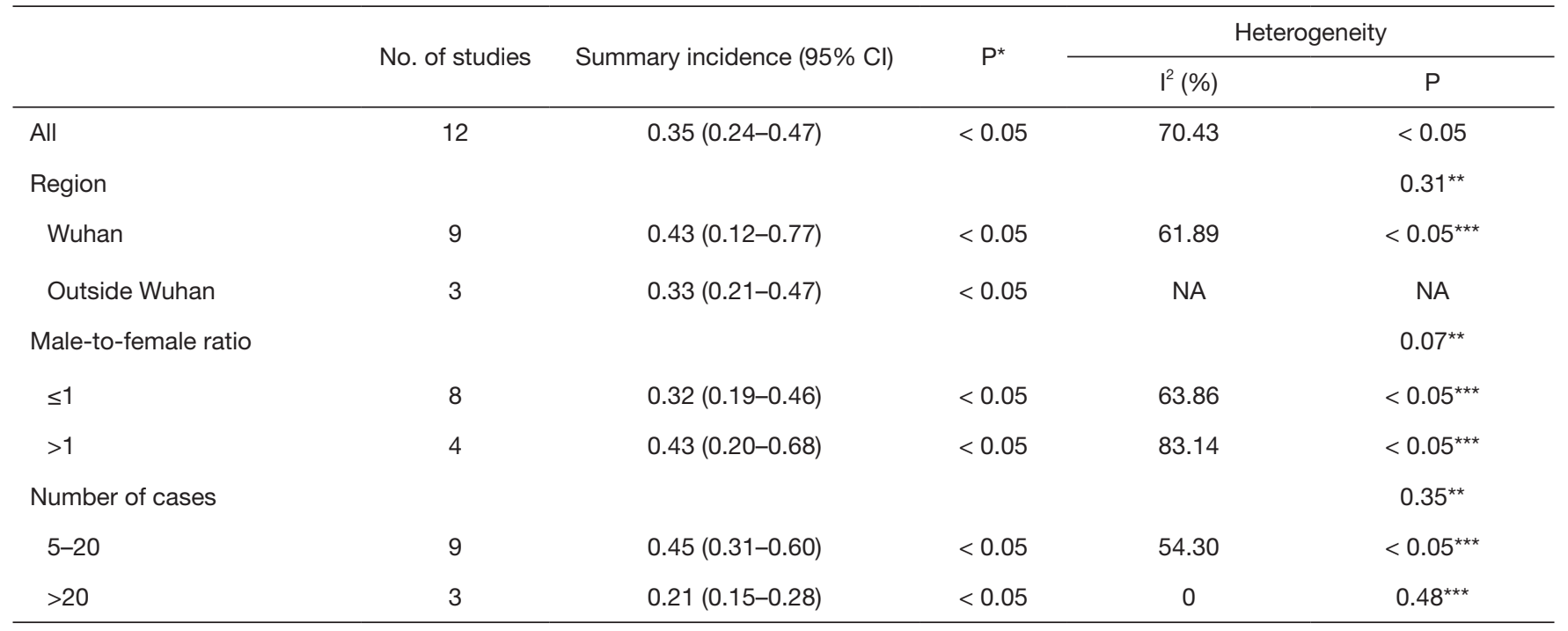

Abbreviations: $\mathrm{Cl}=$ confidence interval; COVID-19 = coronavirus disease 2019; NA = not available.

*Significance of summarized incidences.

**Significance of meta-regression on possible sources of heterogeneity.

*** Significance of subgroup analysis on possible sources of heterogeneity.

$P<0.05$ was regarded as indication of statistical significance. 
Table 9 Meta-regression and subgroup analyses on the incidence of unilateral lesions in pediatric COVID-19 cases

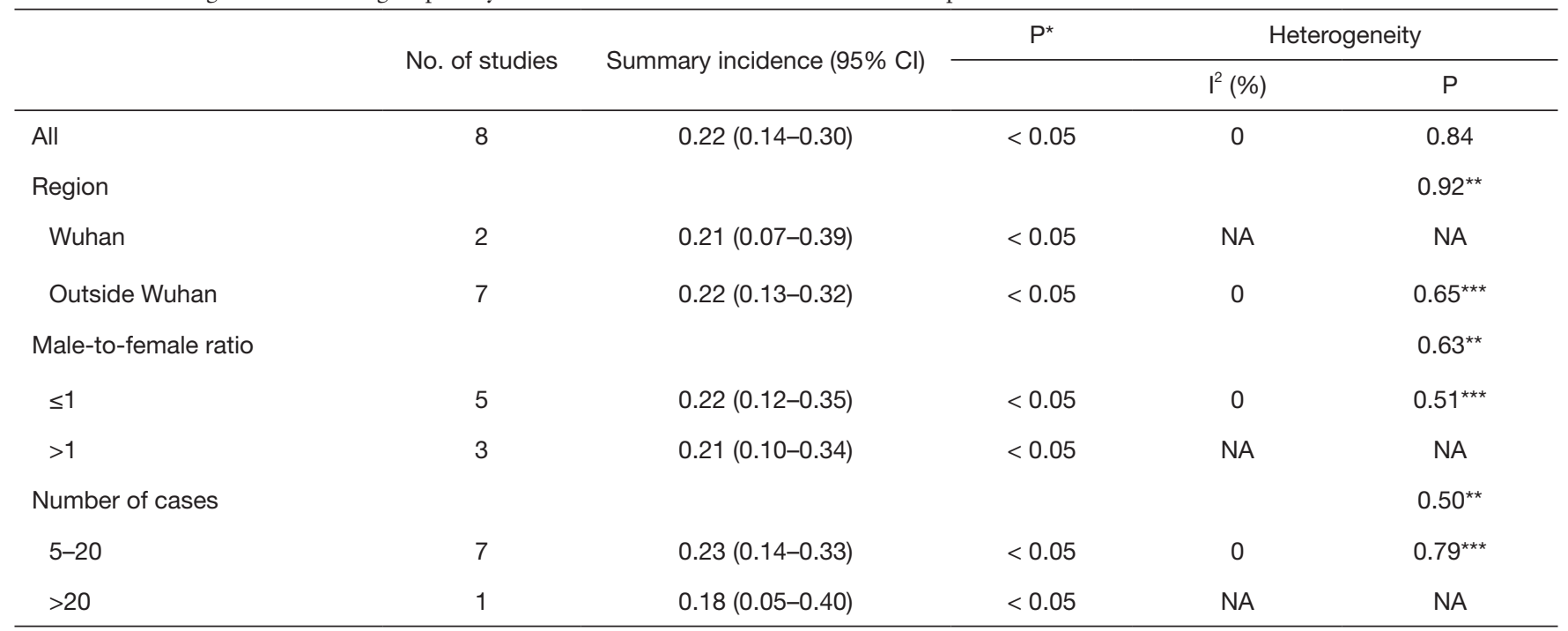

Abbreviations: $\mathrm{Cl}=$ confidence interval; COVID-19 = coronavirus disease 2019; NA = not available.

*Significance of summarized incidences.

**Significance of meta-regression on possible sources of heterogeneity.

${ }^{\star * \star}$ Significance of subgroup analysis on possible sources of heterogeneity.

$\mathrm{P}<0.05$ was regarded as indication of statistical significance.

\section{References (same numbering as the main text)}

8. Liu M, Song Z, Xiao K. High resolution computed tomography manifestations. J Comput Assist Tomogr 2020;44:311-3.

9. Long QX, Tian WG, Deng HJ, et al. The clinical and immunological features of pediatric COVID-19 patients in China. Genes Dis. 2020 Apr 14. Epub. doi:10.1016/ j.gendis.2020.03.008

10. Feng K, Yun Y, Wang X, et al. Analysis of CT features of 15 Children with 2019 novel coronavirus infection 2020. Zhonghua Er Ke Za Zhi 2020;58:275-8.

12. Li B, Shen J, Li L, et al. Radiographic and Clinical Features of Children with Coronavirus Disease (COVID-19) Pneumonia. Indian Pediatr 2020;57:423-6.

13. Li W, Cui H, Li K, et al. Chest computed tomography in children with COVID-19 respiratory infection. Pediatr Radiol 2020;50:796-9.

14. Lu Y, Wen H, Rong D, et al. Clinical characteristics and radiological features of children infected with the 2019 novel coronavirus. Clin Radiol 2020;75:520-5.

15. Ma H, Hu J, Tian J, et al. A single-center, retrospective study of COVID-19 features in children: a descriptive investigation. BMC Med 2020;18:123.

16. Ma YL, Xia SY, Wang M, et al. Clinical features of children with SARS-CoV-2 infection: an analysis of 115 cases. Zhongguo Dang Dai Er Ke Za Zhi 2020;22:290-3.

17. Qiu H, Wu J, Hong L, et al. Clinical and epidemiological features of 36 children with coronavirus disease 2019 (COVID-19) in Zhejiang, China: an observational cohort study. Lancet Infect Dis 2020;20:689-96.

18. Shen Q, Guo W, Guo T, et al. Novel coronavirus infection in children outside of Wuhan, China. Pediatr Pulmonol 2020;55:1424-9.

19. Song W, Li J, Zou N, et al. Clinical features of pediatric patients with coronavirus disease (COVID-19). J Clin Virol 2020;127:104377.

20. Steinberger S, Lin B, Bernheim A, et al. CT Features of Coronavirus Disease (COVID-19) in 30 Pediatric Patients. Am J Roentgenol 2020;215:1-9.

21. Su L, Ma X, Yu H, et al. The different clinical characteristics of corona virus disease cases between children and their families in China - the character of children with COVID-19. Emerg Microbes Infect 2020;9:707-13.

22. Sun $\mathrm{D}, \mathrm{Li} \mathrm{H}, \mathrm{Lu} \mathrm{XX}$, et al. Clinical features of severe pediatric patients with coronavirus disease 2019 in Wuhan: a single center's observational study. World J Pediatr 2020;19:1-9.

23. Tan X, Huang J, Zhao F, et al. Clinical features of children with SARS-CoV-2 infection: an analysis of 13 cases from Changsha, China. Zhongguo Dang Dai Er Ke Za Zhi. 
2020;22:294-8.

24. Tan YP, Tan BY, Pan J, et al. Epidemiologic and clinical characteristics of 10 children with coronavirus disease 2019 in Changsha, China. J Clin Virol 2020;127:104353.

25. Wang D, Ju XL, Xie F, et al. Clinical analysis of 31 cases of 2019 novel coronavirus infection in children from six provinces (autonomous region) of northern China. Zhonghua Er Ke Za Zhi 2020;58:269-74.

26. Wu HP, Li BF, Chen X, et al. Clinical features of coronavirus disease 2019 in children aged $<18$ years in Jiangxi, China: an analysis of 23 cases. Zhongguo Dang Dai Er Ke Za Zhi 2020;22:419-24.

27. Xia W, Shao J, Guo Y, et al. Clinical and CT features in pediatric patients with COVID-19 infection: Different points from adults. Pediatr Pulmonol 2020;55:1169-74.

28. Zheng F, Liao C, Fan QH, et al. Clinical Characteristics of Children with Coronavirus Disease 2019 in Hubei, China. Curr Med Sci 2020;40:275-80.

29. Zhong Z, Xie X, Huang W, et al. Chest CT findings and clinical features of coronavirus disease 2019 in children. Zhong Nan Da Xue Xue Bao Yi Xue Bao 2020;45:236-42.

30. Zhou Y, Yang GD, Feng K, et al. Clinical features and chest CT findings of coronavirus disease 2019 in infants and young children. Zhongguo Dang Dai Er Ke Za Zhi. 2020;22:215-20.

31. Zhu L, Wang J, Huang R, et al. Clinical characteristics of a case series of children with coronavirus disease 2019. Pediatr Pulmonol 2020;55:1430-2. 